\title{
Isotopic constraints on the pre-industrial oceanic nitrogen budget
}

\author{
C. J. Somes ${ }^{1}$, A. Oschlies ${ }^{1}$, and A. Schmittner ${ }^{2}$ \\ ${ }^{1}$ GEOMAR Helmholtz-Zentrum für Ozeanforschung Kiel, Düsternbrooker Weg 20, 24105 Kiel, Germany \\ ${ }^{2}$ College of Earth, Ocean, and Atmospheric Sciences, Oregon State University, 104 CEOAS Admin Bldg., Corvallis, Oregon, \\ 97331, USA
}

Correspondence to: C. J. Somes (csomes@geomar.de)

Received: 4 January 2013 - Published in Biogeosciences Discuss.: 19 February 2013

Revised: 12 July 2013 - Accepted: 15 July 2013 - Published: 6 September 2013

\begin{abstract}
The size of the bioavailable (i.e., "fixed") nitrogen inventory in the ocean influences global marine productivity and the biological carbon pump. Despite its importance, the pre-industrial rates for the major source and sink terms of the oceanic fixed nitrogen budget, $\mathrm{N}_{2}$ fixation and denitrification, respectively, are not well known. These processes leave distinguishable imprints on the ratio of stable nitrogen isotopes, $\delta^{15} \mathrm{~N}$, which can therefore help to infer their patterns and rates. Here we use $\delta^{15} \mathrm{~N}$ observations from the water column and a new database of seafloor measurements to constrain rates of $\mathrm{N}_{2}$ fixation and denitrification predicted by a global three-dimensional Model of Ocean Biogeochemistry and Isotopes (MOBI). Sensitivity experiments were performed to quantify uncertainties associated with the isotope effect of denitrification in the water column and sediments. They show that the level of nitrate utilization in suboxic zones, that is the balance between nitrate consumption by denitrification and nitrate replenishment by circulation and mixing (dilution effect), significantly affects the isotope effect of water column denitrification and thus global mean $\delta^{15} \mathrm{NO}_{3}^{-}$. Experiments with lower levels of nitrate utilization within the suboxic zone (i.e., higher residual water column nitrate concentrations, ranging from 20 to $32 \mu \mathrm{M}$ ) require higher ratios of benthic to water column denitrification, $\mathrm{BD}: \mathrm{WCD}=0.75-1.4$, to satisfy the global mean $\mathrm{NO}_{3}^{-}$and $\delta^{15} \mathrm{NO}_{3}^{-}$constraints in the modern ocean. This suggests that nitrate utilization in suboxic zones plays an important role in global nitrogen isotope cycling. Increasing the net fractionation factor $\varepsilon_{\mathrm{BD}}$ for benthic denitrification $\left(\varepsilon_{\mathrm{BD}}=0-4 \%\right.$ ) requires even higher ratios, $\mathrm{BD}: \mathrm{WCD}=1.4-3.5$. The model experiments that best reproduce observed seafloor $\delta^{15} \mathrm{~N}$ support the middle to high-end estimates for the net fractionation factor of benthic denitrification $\left(\varepsilon_{\mathrm{BD}}=2-4 \%\right.$ ). Assum-
\end{abstract}

ing a balanced fixed nitrogen budget, we estimate that preindustrial rates of $\mathrm{N}_{2}$ fixation, water column denitrification, and benthic denitrification were between 195-350 (225), 6580 (76), and 130-270 (149) $\mathrm{Tg} \mathrm{N} \mathrm{yr}^{-1}$, respectively, with our best model estimate $\left(\varepsilon_{\mathrm{BD}}=2 \%\right)$ in parentheses. Although uncertainties still exist, these results suggest that marine $\mathrm{N}_{2}$ fixation is occurring at much greater rates than previously estimated and the residence time for oceanic fixed nitrogen is between $\sim 1500$ and $3000 \mathrm{yr}$.

\section{Introduction}

Biotically available "fixed" nitrogen (fixed-N) is one of the major nutrients limiting phytoplankton growth in the ocean. Its generally low abundance in sunlit surface waters limits the primary production that forms the base of ocean ecosystems and provides energy for more complex, higher-level organisms (e.g., marine animals). Thereby, fixed-N also limits the biological sequestration of atmospheric carbon dioxide $\left(\mathrm{CO}_{2}\right)$ into biomass, part of which subsequently sinks towards the deep ocean before being respired back into $\mathrm{CO}_{2}$. This so-called "biological carbon pump" affects the partitioning of $\mathrm{CO}_{2}$ among the ocean and atmosphere. It has been suggested that large changes in the oceanic fixed-N inventory can modulate the strength of the biological carbon pump and thereby influence atmospheric $\mathrm{CO}_{2}$ over glacial/interglacial timescales (McElroy, 1983; Falkowski, 1997). Since processes that control the size of the fixed-N inventory are sensitive to climate (Gruber, 2004; Galbraith and Kienast, 2013), they may have an important feedback on atmospheric $\mathrm{CO}_{2}$ concentrations in past and future climates. 
$\mathrm{N}_{2}$ fixation (NFix), the conversion of $\mathrm{N}_{2}$ gas into fixed$\mathrm{N}$ by specialized microorganisms (diazotrophs), provides the ocean with most of its fixed-N. Other contributions to the fixed-N pool are from river input and atmospheric $\mathrm{N}$ deposition, which are estimated to be approximately an order of magnitude lower than NFix in pre-industrial times (Galloway et al., 2004; Codispoti, 2007; Duce et al., 2008; Gruber, 2008). However, industrial $\mathrm{N}$ emissions and fertilizer production through the Haber-Bosch process that eventually cycles fixed-N into the atmosphere and rivers have been steadily increasing in recent decades and are estimated to become comparable to "natural" NFix in following decades (Galloway et al., 2004).

Denitrification and anammox (anaerobic ammonium oxidation) are the most important fixed-N removal processes in the ocean. They convert fixed-N into $\mathrm{N}_{2}$ gas under suboxic conditions $\left(\mathrm{O}_{2}<\sim 10 \mu \mathrm{M}\right)$ in the water column and seafloor sediments. "Canonical" denitrification occurs when heterotrophic bacteria replace $\mathrm{O}_{2}$ consumption with the reduction of nitrate $\left(\mathrm{NO}_{3}^{-}\right)$to dinitrogen gas $\left(\mathrm{N}_{2}\right)$ as the electron acceptor during respiration, once $\mathrm{O}_{2}$ is no longer available in sufficient quantity. Anammox, on the other hand, is a chemoautotrophic process that converts nitrite $\left(\mathrm{NO}_{2}^{-}\right)$ and ammonium $\left(\mathrm{NH}_{4}^{+}\right)$into $\mathrm{N}_{2}$ gas (Thamdrup and Dalsgaard, 2002; Kuypers et al., 2003). Since both denitrification and anammox processes occur in oxygen minimum zones (OMZs), the relative importance of each process is uncertain. Recent studies have found that water column denitrification (WCD) dominates N-loss in the Arabian Sea (Ward et al., 2009; Bulow et al., 2010), while anammox is more important in the eastern tropical South Pacific (ETSP) (Lam et al., 2009). However, Lam et al. (2009) estimate that nitrate reduction, the first step of canonical denitrification, provides at least two-thirds of the nitrite that anammox consumes, suggesting that canonical denitrification may be the most important driver of total N-loss in OMZs. Therefore, we refer to denitrification as the major fixed-N loss process in this paper.

While the major source and sink processes of the fixed-N budget, $\mathrm{N}_{2}$ fixation and denitrification, respectively, are relatively well known, estimating their global rates remains a challenge. Model estimates for $\mathrm{N}_{2}$ fixation have a large range between $\sim 100$ and $300 \mathrm{Tg} \mathrm{N} \mathrm{yr}^{-1}$ and predict different spatial patterns (Gruber and Sarmiento, 1997; Brandes and Devol, 2002; Deutsch et al., 2007; Monteiro et al., 2011; Eugster and Gruber, 2012), whereas estimates based on extrapolation of measured in situ rates agree with the low-end model estimates near $100 \mathrm{Tg} \mathrm{N} \mathrm{yr}^{-1}$ (Karl et al., 2002a; Mahaffey et al., 2005). However, methods historically used to measure $\mathrm{N}_{2}$ fixation rates have been found to underestimate $\mathrm{N}_{2}$ fixation by as much as a factor of 2 (Mohr et al., 2010; Großkopf et al., 2012). Since new important $\mathrm{N}_{2}$-fixing species are also still being discovered (Montoya et al., 2004; Foster et al.,
2011; Zehr, 2011), more $\mathrm{N}_{2}$ fixation could be taking place in the ocean than previously thought.

Global estimates of denitrification vary considerably as well. In the water column, studies suggest global rates between 50 and $150 \mathrm{Tg} \mathrm{Nyr}^{-1}$ and in the sediments generally between 100 and $300 \mathrm{Tg} \mathrm{Nyr}^{-1}$ (Middelburg et al., 1996; Galloway et al., 2004; Gruber, 2004; Codispoti, 2007; Bohlen et al., 2012; DeVries et al., 2013; Eugster and Gruber, 2012). Since the high-end estimates for denitrification are substantially larger than the high-end estimates for $\mathrm{N}_{2}$ fixation, it has led to the debate whether the ocean could be rapidly losing as much as $400 \mathrm{Tg} \mathrm{N} \mathrm{yr}^{-1}$ (Codispoti et al., 2001; Brandes and Devol, 2002; Seitzinger et al., 2006; Codispoti, 2007), about $0.07 \%$ of the total nitrate inventory per year, or whether the nitrogen budget is more balanced (Gruber and Sarmiento, 1997; Gruber, 2004; Altabet, 2007; Bianchi et al., 2012).

Stable nitrogen isotopes can provide constraints on $\mathrm{N}_{2}$ fixation and denitrification because they leave distinguishable imprints on the ratio of oceanic $\delta^{15} \mathrm{~N}$, defined as $\delta^{15} \mathrm{~N}=\left[\left({ }^{15} \mathrm{~N} /{ }^{14} \mathrm{~N}\right)_{\text {sample }} /\left({ }^{15} \mathrm{~N} /{ }^{14} \mathrm{~N}\right)_{\text {std }}-1\right] \cdot 1000 \%$, where the standard (std) is atmospheric $\mathrm{N}_{2}$. The main source of $\delta^{15} \mathrm{~N}$ into the pre-industrial ocean is from diazotrophs that fix ${ }^{15} \mathrm{~N}$-depleted atmospheric $\mathrm{N}_{2}$ into their biomass $\left(\delta^{15} \mathrm{~N}_{\text {Diaz }}=-2-0 \%\right.$ ) relative to the deep ocean $\delta^{15} \mathrm{NO}_{3}^{-}=5 \%$ o (Sigman et al., 2000; Somes et al., 2010b), with minor contributions from atmospheric deposition $\left(\delta^{15} \mathrm{~N}_{\text {dep }}=\sim-4 \%\right.$ ) and rivers $\left(\delta^{15} \mathrm{~N}_{\text {riv }}=\sim 1-4 \%\right.$ ) (Brandes and Devol, 2002). Denitrifying bacteria preferentially consume ${ }^{15} \mathrm{~N}$-depleted nitrate, the lighter and more reactive isotope, during $\mathrm{WCD}\left(\varepsilon_{\mathrm{WCD}}=20-30 \%\right)$, leaving the oceanic nitrate pool ${ }^{15} \mathrm{~N}$-enriched (Cline and Kaplan, 1975; Brandes et al., 1998; Voss et al., 2001). Benthic denitrification (BD) is observed to have a much lower net fractionation factor $\left(\varepsilon_{\mathrm{BD}}=0-3 \%\right)$, which is attributed to near complete $\mathrm{NO}_{3}^{-}$utilization in pore-water sediments (Brandes and Devol, 2002; Lehmann et al., 2004). However, recent studies (Lehmann et al., 2007; Granger et al., 2011; Alkhatib et al., 2012) investigating fractionation involved with the nitrification-denitrification loop in the sediments suggest a larger net fractionation factor $\left(\varepsilon_{\mathrm{BD}}=4-8 \%\right.$ ).

The observed global mean $\delta^{15} \mathrm{NO}_{3}^{-}$provides a constraint on the fixed-N budget (Brandes and Devol, 2002) since it is determined by the relative rates of NFix, WCD and BD and their isotope effects. The input of ${ }^{15} \mathrm{~N}$-depleted nitrogen from NFix must compensate for the preferential removal of ${ }^{15} \mathrm{~N}$-depleted nitrate by denitrification. Modeling studies using this approach have produced differing results. For example, Brandes and Devol (2002) used a one-box model with fractionation factors of $\varepsilon_{\mathrm{BD}}=1.5 \%$ and $\varepsilon_{\mathrm{WCD}}=25 \%$. They estimated a ratio $\mathrm{BD}: \mathrm{WCD}=3.7: 1$ to match global mean $\delta^{15} \mathrm{NO}_{3}^{-}$, supporting the high-end estimates for $\mathrm{BD}$.

Other studies have used more complex box models (Deutsch et al., 2004; Eugster and Gruber, 2012). Assuming $\varepsilon_{\mathrm{BD}}=0 \%$ and $\varepsilon_{\mathrm{WCD}}=25 \%$, these studies estimate a 
lower $\mathrm{BD}$ : WCD ratio of $1.8-2.7$ compared to Brandes and Devol (2002) by accounting for mixing of locally reduced nitrate concentrations in suboxic zones with surrounding oxic waters. Since the mixed $\delta^{15} \mathrm{NO}_{3}^{-}$value will be weighted towards the higher nitrate concentration of the oxic waters, the local utilization of nitrate reduces the influence of the ${ }^{15} \mathrm{~N}$-enriched nitrate from WCD on global mean $\delta^{15} \mathrm{NO}_{3}^{-}$, a mechanism referred to as the "dilution effect" (Deutsch et al., 2004).

Altabet (2007) used another one-box model with parameterized isotope effects of local nitrate utilization and dilution during WCD. He argues that these effects would further reduce the isotope effect of WCD by $\sim 13 \%$ o compared to the inherent microbial process near 25\%. Applying this reduced isotope effect for water column denitrification $(\sim 12 \%)$, and $0 \%$ o for $\mathrm{BD}$, respectively, he estimated a BD : WCD ratio of $\sim 1: 1$. These box model studies highlight how sensitive the results can be to different assumptions made for the isotope effects of denitrification.

In this study, we go beyond earlier box model approaches and employ a global coupled three-dimensional circulationbiogeochemistry-isotope model to investigate to what extent rates of $\mathrm{N}_{2}$ fixation and denitrification can be constrained by $\delta^{15} \mathrm{~N}$ observations in the water column and seafloor sediments. In particular, we will investigate the uncertainties associated with (i) the effects of nitrate utilization and dilution on the isotope effect of WCD and (ii) the net fractionation factor associated with BD. In addition to water column $\delta^{15} \mathrm{NO}_{3}^{-}$observations, a new global seafloor sediment $\delta^{15} \mathrm{~N}$ database (Tesdal et al., 2013) is used to evaluate the model experiments. The rates of $\mathrm{N}_{2}$ fixation and denitrification implicit in the model simulations that most closely simulate observed $\delta^{15} \mathrm{NO}_{3}^{-}$and seafloor $\delta^{15} \mathrm{~N}$ then provide our best estimate of Nfix and denitrification in the real ocean.

\section{Model description}

The global coupled Model of Ocean Biogeochemistry and Isotopes (MOBI) is based on the version of Somes et al. (2010b). A technical description of the model is located in Appendix B and a brief overview is provided below.

\subsection{Physical model}

The physical model is based on the University of Victoria Earth System Climate Model (Weaver et al., 2001), version 2.9 (Eby et al., 2009). It includes a general circulation model of the ocean (Modular Ocean Model 2) with physical parameterizations such as diffusive mixing along and across isopycnals, eddy-induced tracer advection (Gent and McWilliams, 1990), the computation of tidally induced diapycnal mixing over rough topography (Simmons et al., 2004), and an anisotropic viscosity scheme (Large et al., 2001) in the tropics. Nineteen vertical levels are used with a horizontal resolu-

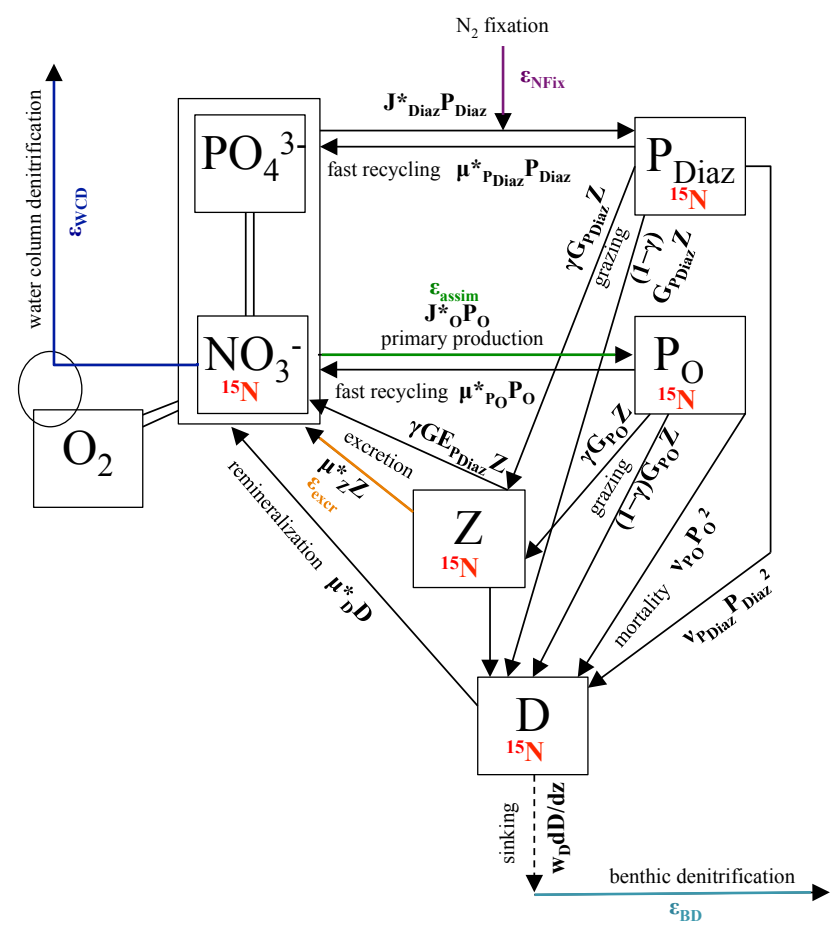

Fig. 1. Schematic of the marine ecosystem/biogeochemical model compartments including the nitrogen isotope parameters (colors) (Somes et al., 2010b). The prognostic variables include 2 nutrients, nitrate $\left(\mathrm{NO}_{3}^{-}\right)$and phosphate $\left(\mathrm{PO}_{4}^{3-}\right), 2$ phytoplankton, $\mathrm{N}_{2-}$ fixing diazotrophs $\left(\mathrm{P}_{\text {Diaz }}\right)$ and other $\mathrm{NO}_{3}^{-}$-assimilating phytoplankton $\left(\mathrm{P}_{\mathrm{O}}\right)$, as well as zooplankton $(\mathrm{Z})$, sinking detritus $(\mathrm{D})$, and dissolved oxygen $\left(\mathrm{O}_{2}\right)$.

tion of $1.8^{\circ} \times 3.6^{\circ}$. A two-dimensional, single-level energymoisture balance model of the atmosphere and a dynamicthermodynamic sea ice model are used, forced with prescribed NCEP/NCAR monthly climatological winds (Kalnay et al., 1996).

\subsection{Biogeochemical-ecosystem model}

MOBI is an improved version of the model used in Somes et al. (2010b) (see Fig. 1). The organic compartments include two classes of phytoplankton, $\mathrm{N}_{2}$-fixing diazotrophs $\left(\mathrm{P}_{\text {Diaz }}\right)$ and other nitrate assimilating phytoplankton $\left(\mathrm{P}_{\mathrm{O}}\right)$, as well as zooplankton ( $\mathrm{Z}$ ) and sinking detritus (D). The inorganic variables include dissolved oxygen $\left(\mathrm{O}_{2}\right)$ and two nutrients, nitrate $\left(\mathrm{NO}_{3}^{-}\right)$and phosphate $\left(\mathrm{PO}_{4}^{3-}\right)$, both of which are consumed by phytoplankton.

This model version deviates from that of Somes et al. (2010b) by including varying elemental stoichiometry. While general phytoplankton nitrogen to phosphorus ratio $(\mathrm{N}: \mathrm{P})$ remains at the canonical Redfield ratio $(\mathrm{N}: \mathrm{P}=16)$, diazotroph $\mathrm{N}: \mathrm{P}$ is set to 40 , which is in better agreement with most observations $(\mathrm{N}: \mathrm{P}=20-50+$; e.g., Letelier and Karl, 1998 and Sañudo-Wilhelmy et al., 2004), as well as an optimality-based growth model (Klausmeier et al., 2004). 
This allows diazotrophs to more efficiently fix $\mathrm{N}_{2}$ into the ocean when they are P-limited, but does not significantly change the pattern of $\mathrm{N}_{2}$ fixation. Since zooplankton are capable of maintaining their own stoichiometry (Sterner and Elser, 2002), we set zooplankton N:P to $16: 1$ and assume that they excrete excess $\mathrm{N}$ when grazing diazotrophs. Detrital $\mathrm{N}$ and $\mathrm{P}$ are explicitly calculated as separate prognostic variables. The carbon to nitrogen $(\mathrm{C}: \mathrm{N})$ ratio for all compartments is held constant at $\mathrm{C}: \mathrm{N}=6.625$.

\subsection{1 $\mathrm{N}_{2}$ fixation}

Diazotrophs grow according to the same principles as the general phytoplankton class in MOBI, but we account for some of their different characteristics as follows. $\mathrm{N}_{2}$ fixation is energetically more costly than assimilating fixed$\mathrm{N}$. Diazotrophs must break down the strong triple-N bond and undergo extra respiration to keep the $\mathrm{N}_{2}$-fixing compartment anoxic since $\mathrm{O}_{2}$ inhibits the expression of the $\mathrm{N}_{2}$-fixing gene (nifH). Thus, the growth rate of diazotrophs is reduced compared to ordinary phytoplankton, which MOBI considers by using a handicap factor $\left(c_{\text {Diaz }}=0.13\right)$. Diazotrophs are allowed to grow at low rates in cool waters according to Eq. (B4), consistent with culture experiments (Pandey et al., 2004; Le Quéré et al., 2005), whereas in previous model versions (Schmittner et al., 2008; Somes et al., 2010b) their growth rates were zero below $15^{\circ} \mathrm{C}$.

Diazotrophs are not limited by nitrate and can outcompete general phytoplankton in surface waters that are depleted in fixed-N, but still contain sufficient phosphate and iron. They will consume nitrate if available, consistent with culture experiments (Mulholland et al., 2001; Holl and Montoya, 2005), which is another factor that inhibits $\mathrm{N}_{2}$ fixation in high-nutrient, low-chlorophyll regions in the model. The prey-capture rate for zooplankton feeding on diazotrophs is reduced relative to that for the general phytoplankton class in order to account for observations (Table 1) (Mulholland, 2007), in contrast to Somes et al. (2010b), who used equal rates.

Due to uncertainties in the iron cycle (Aumont et al., 2003; Moore et al., 2004; Galbraith et al., 2010), iron is currently not included as a prognostic tracer. Instead, iron limitation is considered using a monthly mask based on modeled aeolian dust deposition estimates (Mahowald et al., 2005a, 2006, 2009). This iron limitation mask is multiplied by diazotrophs' maximum growth rate to account for iron limitation (Somes et al., 2010a). Note that this diazotroph iron limitation mask does not account for upwelled iron. Since upwelled iron will be accompanied by other macronutrients, we assume this source of iron is consumed by other phytoplankton. This simplification may lead to an overestimation of iron limitation of diazotrophs in and around some upwelling regions because complete utilization of upwelled iron by other phytoplankton will likely not occur in all of these areas (e.g., Equatorial Atlantic; Subramaniam et al., 2013). We scaled our iron limitation mask of diazotrophs to best reproduce large-scale meridional $\delta^{15} \mathrm{~N}$ patterns across the Pacific and Atlantic oceans.

\subsubsection{Water column denitrification}

WCD occurs when organic matter is respired under suboxic conditions. It is parameterized in MOBI according to Eq. (B14), which determines the relative amount of nitrate consumption that takes place during respiration at low ambient oxygen concentrations. We use a threshold of $5 \mu \mathrm{M} \mathrm{O}_{2}$ that sets the oxygen level at which respiration by denitrification overtakes aerobic respiration. This parameterization was designed to best capture the decreasing $\mathrm{NO}_{3}^{-}: \mathrm{PO}_{4}^{3-}$ ratios in suboxic zones. Anammox is also removing fixed- $\mathrm{N}$ in these areas of low oxygen and high organic matter recycling. Although the exact partitioning between WCD and anammox is not well known, anammox likely depends on the first step of denitrification $\left(\mathrm{NO}_{3}^{-} \rightarrow \mathrm{NO}_{2}^{-}\right)$to supply sufficient nitrite that typically exists in very low concentrations (Lam et al., 2009). Since MOBI does not differentiate between different species of dissolved inorganic nitrogen, this WCD parameterization is designed to implicitly capture total fixed-N loss from both canonical WCD and anammox.

\subsubsection{Benthic denitrification}

BD is included using a new empirical function deduced from benthic flux measurements (Bohlen et al., 2012) . This function estimates denitrification in the sediments based on organic carbon rain rate into the sediments, and bottom water $\mathrm{O}_{2}$ and $\mathrm{NO}_{3}^{-}$concentrations (Eq. B15). It provides an efficient alternative to coupling a full sediment model that would significantly reduce simulation speed. Note that all organic matter instantaneously remineralizes in the bottom water when it reaches the seafloor sediment interface. $\mathrm{Ni}$ trate is then removed from the bottom water according to this benthic denitrification function. While the organic carbon rain rate predicts benthic denitrification rates to firstorder, Bohlen et al. (2012) found a strong non-linear relationship to the empirical parameter $\mathrm{O}_{2}^{*}=\mathrm{O}_{2}-\mathrm{NO}_{3}^{-}$in the bottom water overlying the sediments. $\mathrm{BD}$ rates are significantly higher as $\mathrm{O}_{2}^{*}$ decreases (i.e., when $\mathrm{O}_{2}$ is low and $\mathrm{NO}_{3}^{-}$ is high) for similar organic carbon rain rates.

We use high resolution $\left(1 / 5^{\circ}\right)$ bathymetry to account for shallow continental shelves and other topographical features that are not fully resolved in MOBI's coarse-resolution grid in order to calculate BD (Eq. B15). This scheme considers particulate organic matter sinking and remineralization, but it does not influence the physical circulation. Since details of the circulation that are not resolved in our global model are responsible for nutrient fluxes in these areas (Fennel et al., 2006), our model will likely underestimate productivity, rain rate of carbon into the seafloor, and thus BD there if the BD rate is not further adjusted. This is one of the reasons why 
Table 1. Model experiment parameter settings. Parameters are the nitrate threshold for the limitation of WCD (limWCD), BD fractionation $\left(\varepsilon_{\mathrm{BD}}\right)$, scaling factor for $\mathrm{BD}$ rate $\left(\alpha_{\mathrm{BD}}\right)$, prey-capture rate for zooplankton grazing on diazotrophs $\left(\omega_{\text {Diaz }}\right)$, and mortality of diazotrophs $\left(v_{\text {Diaz }}\right)$.

\begin{tabular}{cccccc}
\hline Experiment & $\begin{array}{c}\operatorname{limWCD} \\
{\left[\mu \mathrm{M} \mathrm{NO}_{3}^{-}\right]}\end{array}$ & $\begin{array}{c}\varepsilon_{\mathrm{BD}} \\
{[\% o]}\end{array}$ & $\alpha_{\mathrm{BD}}$ & $\begin{array}{c}\omega_{\text {Diaz }} \\
{\left[\mathrm{mmol} \mathrm{m}^{-3}\right]^{-2} \mathrm{~d}^{-1}}\end{array}$ & $\begin{array}{c}v_{\text {Diaz }} \\
{\left[{ }^{-1}\right]}\end{array}$ \\
\hline 1 & 20 & 0 & 1.35 & 0.11 & 0.25 \\
2 & 26 & 0 & 1.55 & 0.1 & 0.25 \\
3 & 32 & 0 & 1.5 & 0.15 & 0.25 \\
4 & 32 & 2 & 1.9 & 0.078 & 0.25 \\
5 & 32 & 4 & 3.2 & 0.001 & 0.17 \\
\hline
\end{tabular}

See text and Table $\mathrm{B} 1$ for additional details.

we provide sensitivity experiments that linearly increase $\mathrm{BD}$ rates by different factors $\left(\alpha_{\mathrm{BD}}=1.35-3.2\right.$; Tables 1,2$)$. Note that water in contact with this subgrid-scale shelf scheme can still be influenced from water below through physical mixing and circulation that can result in too much coupling with the ocean interior.

\subsection{Nitrogen isotope model}

The nitrogen isotope model simulates the two stable nitrogen isotopes, ${ }^{14} \mathrm{~N}$ and ${ }^{15} \mathrm{~N}$, in all $\mathrm{N}$ species included in MOBI. Fractionation results in the preferential incorporation of the more reactive, thermodynamically preferred ${ }^{14} \mathrm{~N}$ isotope into the product of each reaction by a process-specific fractionation factor, $\alpha$ (Mariotti et al., 1981). We report these values in the more commonly used " $\delta$ " notation, where the fractionation factor takes the form $\varepsilon=(1-\alpha) \times 1000$. The processes in the model that fractionate nitrogen isotopes are phytoplankton nitrate assimilation $\left(\varepsilon_{\text {assim }}=5 \%\right), \mathrm{N}_{2}$ fixation $\left(\varepsilon_{\mathrm{NFix}}=1.5 \%\right)$, zooplankton excretion $\left(\varepsilon_{\mathrm{excr}}=6 \%\right)$, WCD $\left(\varepsilon_{\mathrm{WCD}}=25 \%\right)$, and $\mathrm{BD}\left(\varepsilon_{\mathrm{BD}}=0,2,4 \% o\right)$. For example, diazotroph biomass becomes $1.5 \%$ o depleted in $\delta^{15} \mathrm{~N}$ relative to the source (atmospheric $\delta^{15} \mathrm{~N}_{2}=0 \%$ ) giving diazotroph biomass a $\delta^{15} \mathrm{~N}$ signature of $-1.5 \%$ when they fix atmospheric $\mathrm{N}_{2}$ for growth.

We refer to the fractionation factor as the $\varepsilon$ value chosen for the fractionation equation and the "isotope effect" as the overall effect the process has on the $\delta^{15} \mathrm{~N}$ distribution in the ocean. The total isotope effect also includes effects from source values and processes that alter the impact of the net fractionation, such as nitrate utilization and dilution. NFix, for example, has a low fractionation factor, but a strong isotope effect by introducing very ${ }^{15} \mathrm{~N}$-depleted nitrogen $\left(\delta^{15} \mathrm{~N}_{\mathrm{NFix}}=-1.5 \%\right.$ o into the oceanic fixed-N pool relative to deep ocean mean $\delta^{15} \mathrm{NO}_{3}^{-}$near $5 \%$ o. In MOBI, fractionation factors are constant in space and time, and chosen to best represent estimates from field observations (Somes et al., 2010b).

\subsection{Sensitivity experiments}

The model experiments were initialized with World Ocean Atlas 2009 (WOA09) observations (temperature, salinity, oxygen, nitrate, and phosphate) (Antonov et al., 2010; Garcia et al., 2010a, b; Locarnini et al., 2010) and integrated for over $10000 \mathrm{yr}$ with pre-industrial boundary conditions as the nitrogen cycle approached equilibrium. While the scarcity of water column observations makes it difficult to estimate global mean $\delta^{15} \mathrm{NO}_{3}^{-}$, vertical $\delta^{15} \mathrm{NO}_{3}^{-}$profiles throughout the global ocean converge to $\sim 5 \%$ at depths below $2000 \mathrm{~m}$ (Somes et al., 2010b). In our experiments we manually adjust the global NFix and BD rates to match this deep ocean $\delta^{15} \mathrm{NO}_{3}^{-}$value and observed global mean $\mathrm{NO}_{3}^{-} \cong 30.8 \mu \mathrm{M}$ by modifying uncertain parameters (Tables 1,2). Adjusting $\alpha_{\mathrm{BD}}$ determines the total $\mathrm{BD}$ rate. For NFix, we adjust the preycapture rate, $\omega_{\text {Diaz }}$, and mortality rate, $v_{\text {Diaz }}$, of diazotrophs, which regulate their net growth. In the following sections, annual mean results from the final $500 \mathrm{yr}$ of the integrations are reported.

\subsubsection{Water column denitrification experiments}

This set of experiments was designed to test the importance of the isotope effect of WCD on the global ocean mean $\delta^{15} \mathrm{NO}_{3}^{-}$. We follow a method introduced by Moore and Doney (2007) that limits the rate of WCD (limWCD) at nitrate thresholds of 20,26, and $32 \mu \mathrm{M}$ (Table 2, Fig. 2). These values were chosen to produce WCD rates that lie within the range of modern estimates between 50 and $150 \mathrm{Tg} \mathrm{N} \mathrm{yr}^{-1}$. Note that recent studies report a new low-end estimate for water column denitrification rate $\left(\sim 50 \mathrm{Tg} \mathrm{N} \mathrm{yr}^{-1}\right)$ (Eugster and Gruber, 2013; DeVries et al., 2013), which is not explicitly tested in our model experiments that cover the range $75-140 \mathrm{Tg} \mathrm{N} \mathrm{yr}^{-1}$.

Only the highest threshold applied $(\operatorname{limWCD}=32)$ captures the average nitrate concentration in the suboxic zones suggested by WOA09 $(\sim 32 \mu \mathrm{M})$, while the other experiments underestimate nitrate there. Models with higher thresholds also have lower levels of nitrate utilization in the suboxic zones that influences the isotope effect of WCD. In order to exclude impacts on the distribution of other biogeochemical tracers (oxygen, phosphate), remineralization of organic matter was left unchanged in these sensitivity experiments. Only nitrate consumption during WCD was turned off below the respective nitrate threshold.

\subsubsection{Benthic denitrification fractionation experiments}

Field studies estimate the fractionation factor of BD to be much smaller than that of water column denitrification, but to what extent still remains uncertain. The small increase in bottom water $\delta^{15} \mathrm{NO}_{3}^{-}$overlying $\mathrm{BD}$ zones suggests the fractionation factor should be in the range 0-3\%o (Brandes and Devol, 2002; Lehmann et al., 2004). However, more 
Table 2. Model sensitivity experiment results.

\begin{tabular}{|c|c|c|c|c|c|c|c|c|c|c|c|c|}
\hline \multicolumn{3}{|c|}{ Experiment } & \multicolumn{7}{|c|}{ Global results } & \multicolumn{3}{|c|}{ Suboxic zone results } \\
\hline$\#$ & $\begin{array}{c}\lim \mathrm{WCD} \\
(\mu \mathrm{M} \\
\left.\mathrm{NO}_{3}^{-}\right)\end{array}$ & $\begin{array}{l}\varepsilon_{\mathrm{BD}} \\
(\% \circ)\end{array}$ & $\begin{array}{c}\mathrm{N}_{2} \\
\text { fixation } \\
(\mathrm{Tg} \mathrm{N} \\
\left.\mathrm{yr}^{-1}\right)\end{array}$ & $\begin{array}{c}\text { WC } \\
\text { deni. } \\
\left(\mathrm{Tg} \mathrm{N}^{-1}\right. \\
\left.\mathrm{yr}^{-1}\right)\end{array}$ & $\begin{array}{c}\text { Benthic } \\
\text { deni. } \\
(\mathrm{TgN} \\
\left.\mathrm{yr}^{-1}\right)\end{array}$ & $\begin{array}{l}\text { BD : } \\
\text { WCD }\end{array}$ & $\begin{array}{c}\mathrm{NO}_{3}^{-} \\
(30.8 \\
\mu \mathrm{M})\end{array}$ & $\begin{array}{c}\text { Deep } \\
\text { ocean } \\
\delta^{15} \mathrm{NO}_{3}^{-} \\
(5.0 \% 0)\end{array}$ & $\begin{array}{c}\text { Global } \\
\text { ocean } \\
\delta^{15} \mathrm{NO}_{3}^{-} \\
(\sim 5.5 \%)\end{array}$ & $\begin{array}{l}\mathrm{NO}_{3}^{-} \\
(33.5 \\
\mu \mathrm{M})\end{array}$ & $\begin{array}{l}\delta^{15} \mathrm{NO}_{3}^{-} \\
(\sim 12 \% \text { o })\end{array}$ & $\begin{array}{c}\mathrm{NO}_{3}: 15 \mathrm{PO}_{4} \\
\quad(0.760)\end{array}$ \\
\hline 1 & 20 & 0 & 248 & 140 & 108 & 0.77 & 31.0 & 4.95 & 5.51 & 24.8 & 17.5 & 0.549 \\
\hline 2 & 26 & 0 & 232 & 109 & 123 & 1.13 & 30.8 & 5.01 & 5.59 & 28.7 & 15.9 & 0.635 \\
\hline 3 & 32 & 0 & 203 & 86.4 & 117 & 1.39 & 30.2 & 5.01 & 5.59 & 33.3 & 14.1 & 0.722 \\
\hline 4 & 32 & 2 & 225 & 75.7 & 149 & 1.96 & 30.6 & 5.01 & 5.53 & 33.2 & 13.6 & 0.734 \\
\hline 5 & 32 & 4 & 342 & 75.6 & 267 & 3.53 & 30.4 & 5.06 & 5.45 & 32.9 & 11.9 & 0.789 \\
\hline
\end{tabular}

Model results for the different sensitivity experiments in the global ocean and suboxic zone $\left(\mathrm{O}_{2}<10 \mu \mathrm{M}\right)$ with the observational estimate given in parentheses.

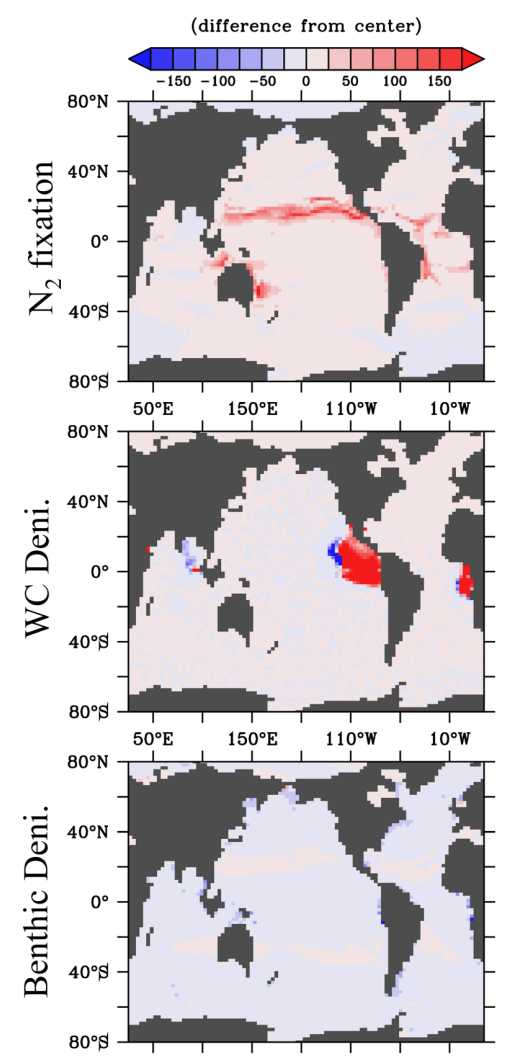

$\lim \mathrm{WCD}=20, \varepsilon_{\mathrm{BD}}=0$

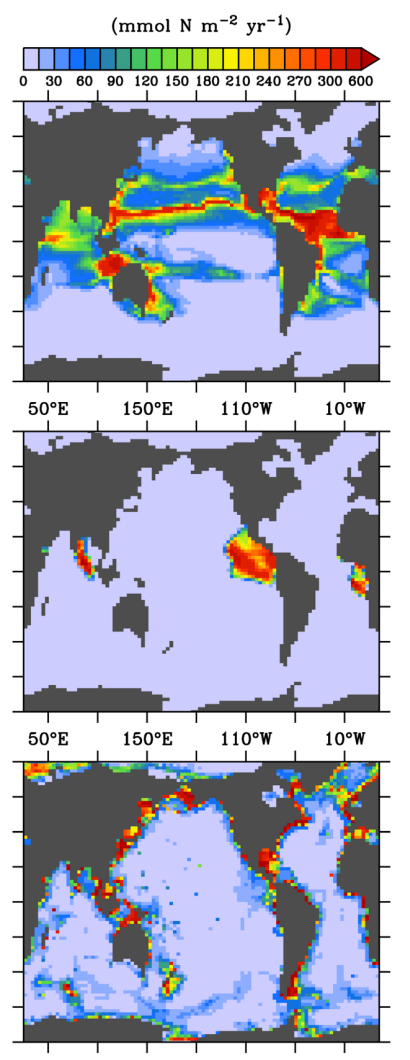

$\lim \mathrm{WCD}=32, \varepsilon_{\mathrm{BD}}=0$
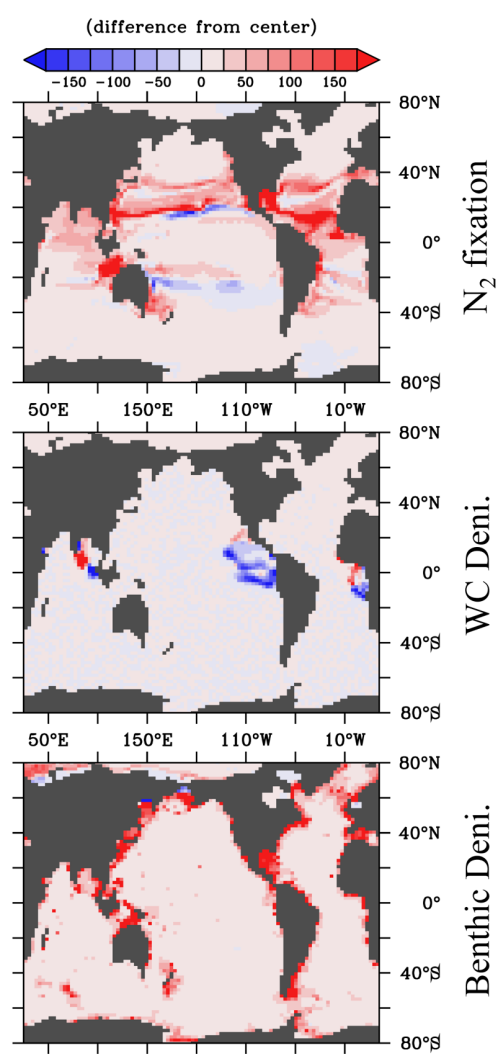

$\lim \mathrm{WCD}=32, \varepsilon_{\mathrm{BD}}=4$

Fig. 2. Global distribution of annual vertically integrated $\mathrm{N}_{2}$ fixation (top row), water column denitrification (middle row) and benthic denitrification (bottom row) for the experiments limWCD $=20, \varepsilon_{\mathrm{BD}}=0$ (left); limWCD $=32, \varepsilon_{\mathrm{BD}}=0$ (center); and limWCD $=32, \varepsilon_{\mathrm{BD}}=4$ (right). See text for model experiment details.

recent studies have suggested a much higher net fractionation (Lehmann et al., 2007; Granger et al., 2011; Alkhatib et al., 2012). They suggest the ${ }^{15} \mathrm{~N}$-enriched ammonium measured in the overlying bottom water, presumably released from the sediments, was due to fractionation during the nitrificationdenitrification loop in the sediments. These studies indicate a net fractionation factor for $\mathrm{BD}$ in the range $4-8 \%$.
However, Lehmann et al. (2007) show that shallow regions have a higher net fractionation compared to deep ocean sites and the global average net fractionation is likely closer to $4 \%$. Thus we performed experiments with BD net fractionation at 0,2 , and $4 \%$. Since these experiments nearly cover the full range of previous estimates for BD rates between $\sim 100-300 \mathrm{Tg} \mathrm{N} \mathrm{yr}^{-1}$ and BD's net fractionation factor, they 
likely test the full range of uncertainty of BD's effect on the global nitrogen isotope inventory.

\section{Results}

\subsection{Patterns of $\mathrm{N}_{2}$ fixation and denitrification}

\subsection{1 $\mathrm{N}_{2}$ fixation}

Diazotrophs perform $\mathrm{N}_{2}$ fixation primarily in the tropics/subtropics where sufficient atmospheric Fe deposition occurs (e.g., North Atlantic, western Pacific, and north Indian Ocean; Fig. 2). Besides temperature and Fe availability, another important factor that determines where model diazotrophs are most abundant includes competition for resources with other phytoplankton (i.e., $\mathrm{N}$ vs. P limitation).

Denitrification consumes nitrate and increases $\mathrm{N}$ limitation "downstream" of denitrification zones. In MOBI, this creates ecological niches for diazotrophs because they are not limited by nitrate. This applies not only to the three WCD zones, but also to the BD zones that occur with greater global rates and across all ocean basins. In fact, it is the higher BD rates in the Atlantic Ocean that stimulate higher $\mathrm{N}_{2}$ fixation rates there in experiment \#5 (Fig. 2, right panel) compared to experiment \#3 (Fig. 2, center panel). Nitrate depletion at the surface thus stimulates $\mathrm{N}_{2}$ fixation as long as temperatures are high enough and sufficient $\mathrm{Fe}$ and $\mathrm{P}$ is available. The spatial pattern of $\mathrm{N}_{2}$ fixation is similar in all experiments, but with differing rates depending on the total denitrification rate in each experiment.

\subsubsection{Water column denitrification}

In MOBI WCD occurs when organic matter is respired in suboxic zones of the eastern tropical North/South Pacific, the Bay of Bengal, and the eastern tropical Atlantic (Fig. 2). Note that in the real ocean, large rates of WCD have been observed in the Arabian Sea, which is not reproduced in the model. Instead, the model displaces the suboxic zone to the Bay of Bengal, which is very close to the suboxic threshold in nature. Similar discrepancies between simulated and observed regions of WCD in the Indian Ocean have also been found in other models (Moore and Doney, 2007; Gnanadesikan et al., 2012). Its causes are not fully understood and may include a misrepresentation of coastal currents or precipitation in the Indian Ocean. Although denitrification is not regularly observed in the Atlantic Ocean, anammox has been measured in the eastern tropical South Atlantic suggesting that N-loss events can occur there (Kuypers et al., 2005). Nevertheless, the model likely significantly overestimates water column $\mathrm{N}$ loss in the Atlantic Ocean.

Uncertainties in historical $\mathrm{O}_{2}$ measurements and interpolation methods to a global scale make it difficult to assess the global volume of suboxic waters in MOBI. The global suboxic volume $\left(\mathrm{O}_{2}<10 \mu \mathrm{M}\right)$ in our experiments is approx- imately 3 times larger than suggested by uncorrected annual WOA09 observations (Garcia et al., 2010a). However, Bianchi et al. (2012) found that after correcting for biases in historical $\mathrm{O}_{2}$ measurements in suboxic zones and applying improved mapping/interpolation methods, this observational dataset is likely underestimating the global volume of suboxic waters by a factor of 3 , which would be in general agreement with our model experiments.

Despite the uncertainty in global suboxic volume, it remains clear that the suboxic zones in the Pacific and Atlantic are displaced over the productive equatorial regions, where the large amounts of remineralization that occurs in the water column would be expected to result in too much WCD. This model bias can be attributed to the underestimation of equatorial and coastal undercurrents that ventilate the OMZs. To account for this model deficiency, we provide sensitivity experiments that limit WCD in the upper part of the OMZ at given $\mathrm{NO}_{3}^{-}$thresholds to produce WCD rates that are within previous estimates (see Sect. 2.4.1) and produce more realistic $\delta^{15} \mathrm{NO}_{3}^{-}$values and $\mathrm{NO}_{3}^{-}$utilization levels in the suboxic zones (see Sect. 3.2.2). Note that the suboxic zones in MOBI also extend too deep in the water column (to $\sim 1500 \mathrm{~m}$ ), whereas according to WOA09 observations they do not extend below $\sim 1000 \mathrm{~m}$. Since remineralization rates are much lower at these depths, only $15 \%$ of total WCD occurs here which suggests that our best model may still be overestimating WCD by $\sim 15 \%$.

\subsubsection{Benthic denitrification}

BD occurs where large amounts of particulate organic carbon (POC) sink into the seafloor sediments (Middelburg et al., 1996; Seitzinger et al., 2006; Fennel et al., 2009; Bohlen et al., 2012). The largest BD rates in the model occur on the continental shelves when primary production is high (e.g., Bering Sea Shelf, Fig. 2). Although rates are much lower in the deep seafloor due to less sinking POC, it contains a much larger area and still significantly contributes to the global $\mathrm{BD}$ rate in the model. The percentage of total $\mathrm{BD}$ (including $\left.\alpha_{\mathrm{BD}}\right)$ simulated on the continental shelves $(0-200 \mathrm{~m})$, slopes (200-2000 m), and deep seafloor (2000-6000 m) is approximately $40 \%, 40 \%$, and $20 \%$, respectively, which does not vary by more than $\pm 5 \%$ for the different model experiments. BD occurs across all ocean seafloor basins and thus has a more broad global distribution compared to WCD, which is confined to three distinct tropical regions (Fig. 2).

\subsection{Observational $\delta^{15} \mathrm{~N}$ constraints}

\subsubsection{Seafloor $\delta^{15} N$}

We compare sinking $\delta^{15} \mathrm{~N}$ in the model with a new global database of seafloor $\delta^{15} \mathrm{~N}$ (Tesdal et al., 2013) (Fig. 3). It is composed of 2347 bulk $\delta^{15} \mathrm{~N}$ measurements covering all ocean basins. This seafloor $\delta^{15} \mathrm{~N}$ database provides a more 


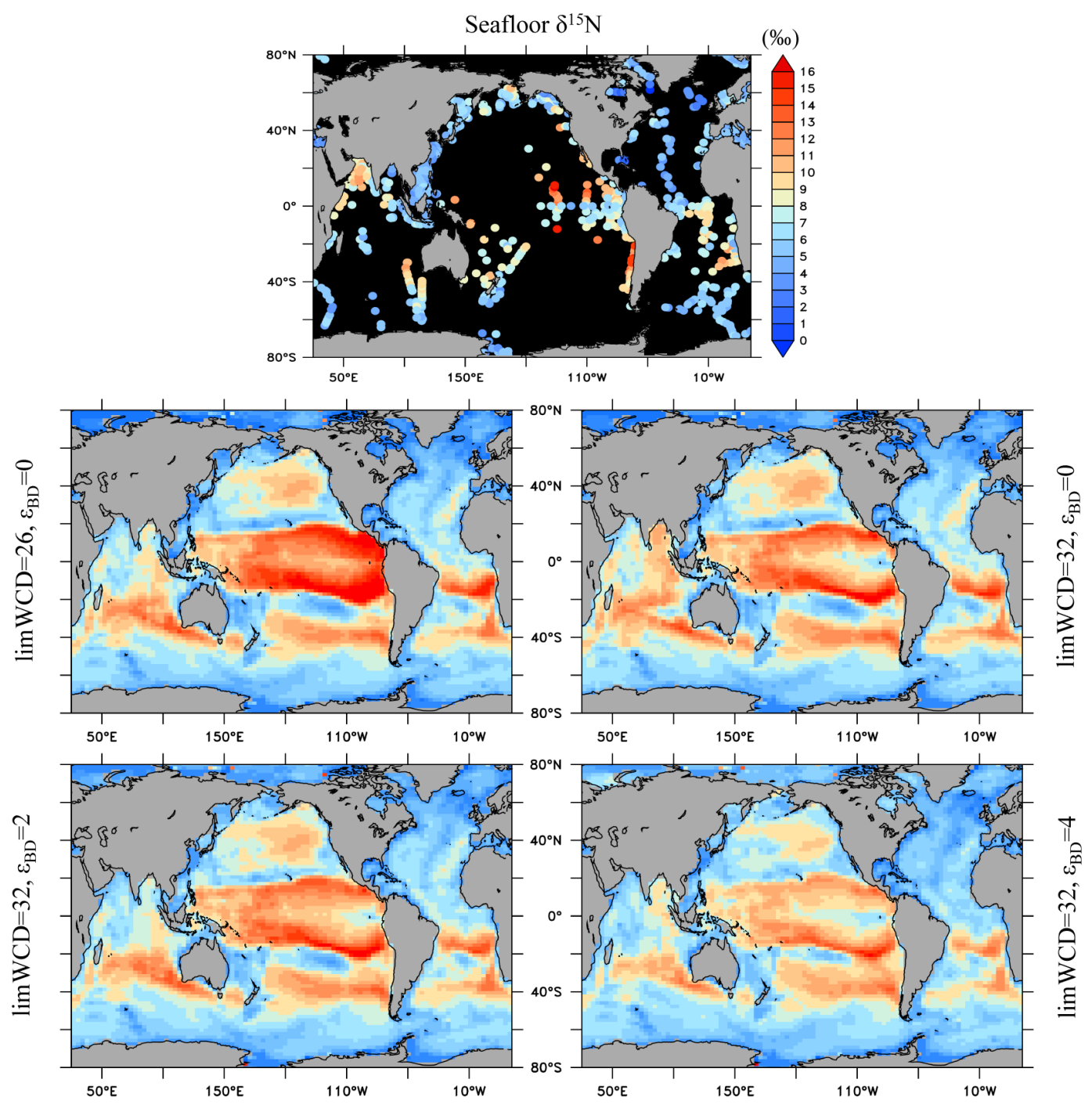

Fig. 3. Seafloor $\delta^{15} \mathrm{~N}$ (Tesdal et al., 2012) comparison with model seafloor $\delta^{15} \mathrm{~N}$ with limWCD $=26, \varepsilon_{\mathrm{BD}}=0$; and limWCD $=32$, $\varepsilon_{\mathrm{BD}}=0$, 2 , and $4 \%$ for all experiments shown here. Note a simple diagenetic model was applied to model sinking $\delta^{15} \mathrm{~N}$ to account for diagenetic alteration during burial into the seafloor sediments based on seafloor depth (Robinson et al., 2012). See text for additional details.

complete view of the global nitrogen isotope distribution compared to available water column $\delta^{15} \mathrm{NO}_{3}^{-}$observations, which are sparse in space and time (Somes et al., 2010b). Since seafloor $\delta^{15} \mathrm{~N}$ measurements represent the accumulation of material spanning the last hundreds to thousands of years, they remove seasonal, interannual, or anthropogenic variability that can impact any single water column observation, making seafloor $\delta^{15} \mathrm{~N}$ an ideal dataset to constrain the long-term average of the pre-industrial ocean.

Diagenetic alteration of $\delta^{15} \mathrm{~N}$ occurs as sinking $\delta^{15} \mathrm{~N}$ becomes buried in seafloor sediments, which can potentially bias the interpretation of bulk sediment $\delta^{15} \mathrm{~N}$. A recent analysis shows a clear relationship of diagenetic alteration with water depth (Robinson et al., 2012). Data at $>50$ sites where sinking $\delta^{15} \mathrm{~N}$ from traps were compared to seafloor $\delta^{15} \mathrm{~N}$ show a $\sim 0.8-1 \%$ o $\delta^{15} \mathrm{~N}$ diagenetic increase per kilometer of water depth. In our model-data comparison, we accordingly adjust the simulated sinking $\delta^{15} \mathrm{~N}$ of the particulate organic nitrogen $(\mathrm{PON})$ reaching the seafloor by increasing it by $0.9 \% \mathrm{~km}^{-1}$ to account for this effect that is not incorporated into MOBI. This diagenetic enrichment increases the globally averaged $\delta^{15} \mathrm{~N}-\mathrm{PON}$ in the sediments by $3.36 \%$ o in the model experiments performed here and makes global mean values consistent with the observations (Table 3). Note that this seafloor diagenesis adjustment is only applied for the model-data comparison and does not affect isotope mass conservation in the model. The data-masked global seafloor $\delta^{15} \mathrm{~N}$ average varies somewhat depending on rates of $\mathrm{N}_{2}$ fixation and denitrification in the different model experiments, but all model experiments show similar values across the 
Table 3. Measures of seafloor $\delta^{15} \mathrm{~N}$ model performance*.

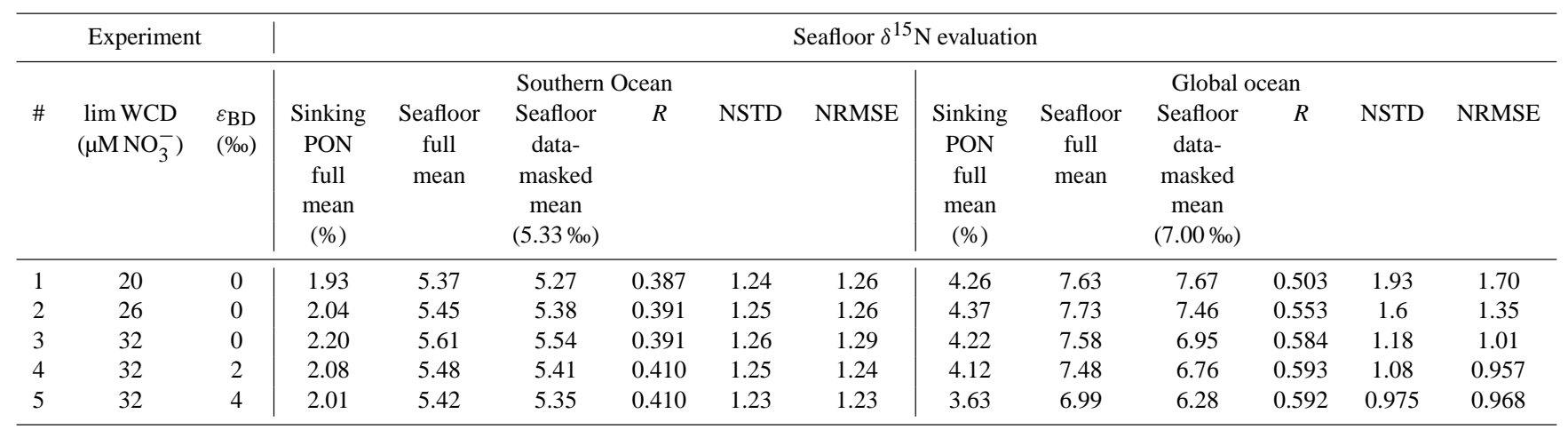

* Statistical measures are the correlation coefficient $(R)$, the normalized (by the STD of the observations) standard deviation (NSTD), and the normalized (by the STD of the observations) root mean squared error (NRMSE). Observational estimates, where available, are given in parentheses. Note "full mean" refers to the entire ocean basin, whereas "data-masked mean" only include grid points where observations exist.

Southern Ocean (Table 3), which is not significantly affected by denitrification and $\mathrm{N}_{2}$ fixation.

MOBI reproduces the major trends of the seafloor $\delta^{15} \mathrm{~N}$ dataset (Fig. 3). The isotope effects of phytoplankton $\mathrm{NO}_{3}^{-}$ assimilation, WCD, and $\mathrm{N}_{2}$ fixation are mainly responsible for these large-scale patterns of $\delta^{15} \mathrm{~N}$ in the model. Relatively ${ }^{15} \mathrm{~N}$-depleted sinking nitrogen hitting the seafloor $\left(\delta^{15} \mathrm{~N}=0-4 \%\right.$ ) occur in high-nutrient, low-chlorophyll regions of the Southern Ocean and eastern equatorial Pacific where $\mathrm{NO}_{3}^{-}$utilization by phytoplankton is low. Here phytoplankton are able to preferentially incorporate ${ }^{15} \mathrm{~N}$-depleted nitrate into their biomass due to high availability of nitrate $\left(\varepsilon_{\text {assim }}=5 \%\right)$. The nitrate utilization isotope effect also produces more ${ }^{15} \mathrm{~N}$-enriched nitrate in surface waters as utilization increases. In the subtropical gyres where nitrate is nearly fully utilized, phytoplankton must consume this ${ }^{15} \mathrm{~N}$ enriched nitrate remaining in the surface water, causing much higher sinking $\delta^{15} \mathrm{~N}$ values there $(>6 \%$ ), in the absence of $\mathrm{N}_{2}$ fixation. All model experiments produce similar patterns and regional averages across the Southern Ocean where surface $\mathrm{NO}_{3}^{-}$utilization dominates the $\delta^{15} \mathrm{~N}$ trend (Table 3, Fig. 4).

Very high seafloor $\delta^{15} \mathrm{~N}$ values $(>10 \%)$ are observed near suboxic zones due to the large fractionation factor of WCD. Modeling the correct extent of the suboxic zones remains a challenge in global coarse-resolution models due to the limited spatial extent of suboxic zones. While the suboxic zones are generally simulated in the correct ocean basins (e.g., eastern tropical Pacific, northern Indian), they are all displaced in the model. Since WCD has a strong local effect on $\delta^{15} \mathrm{~N}$, this displacement causes rather poor model fits when comparing to the seafloor $\delta^{15} \mathrm{~N}$ database (e.g., $r<0.6$, Table 3). If all OMZ regions with less than $30 \mu \mathrm{M}$ dissolved $\mathrm{O}_{2}$ in the model and WOA09 are not included when calculating the global metrics, the correlation coefficient increases from 0.59 to 0.68 (in model experiment \#4), an indication that the bias due to the displaced suboxic zones is one of the

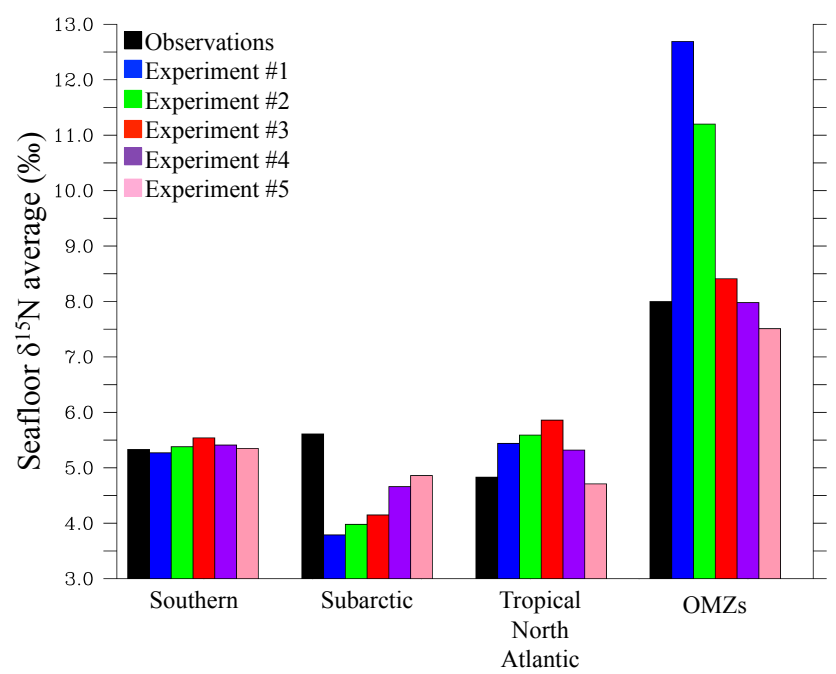

Fig. 4. Comparison of average seafloor $\delta^{15} \mathrm{~N}$ in the Southern Ocean $\left(50-75^{\circ} \mathrm{S}\right)$, subarctic/Arctic Ocean $\left(50-75^{\circ} \mathrm{N}\right)$, tropical North Atlantic $\left(0-25^{\circ} \mathrm{N}\right)$, and oxygen minimum zones $\left(\mathrm{O}_{2}<10 \mu \mathrm{M}\right)$ with observational values in parenthesis. Note we include locations of observed and simulated OMZs to account for the displaced model OMZs in this comparison.

main deficiencies of the model. The model experiments that contain the lowest amount of WCD (limWCD $=32)$ represent the seafloor $\delta^{15} \mathrm{~N}$ database the best (Table 3, Fig. 4).

$\mathrm{N}_{2}$ fixation introduces ${ }^{15} \mathrm{~N}$-depleted nitrogen $\left(\delta^{15} \mathrm{~N}_{\mathrm{NFix}}=-1.5 \%\right.$ o $)$ into the ocean. It occurs primarily in tropical/subtropical waters "downstream" of both WCD and BD zones where nitrate has been depleted relative to phosphate and aeolian Fe deposition is high. Aeolian $\mathrm{Fe}$ deposition is generally higher in the western portion of the ocean basins and in the Northern Hemisphere. In MOBI, this causes a trend of lower sinking $\delta^{15} \mathrm{~N}$ values in the northern subtropical gyres, which is supported by the observational 
seafloor $\delta^{15} \mathrm{~N}$ (Fig. 3), as well as water column observations (Somes et al., 2010a).

Lowest values of seafloor $\delta^{15} \mathrm{~N}$ occur in the North Atlantic, which is known to support high rates of $\mathrm{N}_{2}$ fixation (Karl et al., 2002b). The model experiment that best reproduces these low values there has the highest rate of global $\mathrm{N}_{2}$ fixation (Fig. 4). This model experiment also has the highest rate of $\mathrm{BD}$, which removes fixed-N and stimulates additional $\mathrm{N}_{2}$ fixation (Fig. 2). Note that atmospheric nitrogen deposition is not included in this model version. Since pre-industrial deposition rates are estimated to be approximately an order magnitude lower than $\mathrm{N}_{2}$ fixation (Duce et al., 2008), it likely has a small effect in this pre-industrial scenario. However, atmospheric $\mathrm{N}$ deposition can introduce even more ${ }^{15} \mathrm{~N}$-depleted nitrogen in the North Atlantic $\left(\delta^{15} \mathrm{~N} \cong-4 \%\right.$ ) (Ryabenko et al., 2012), which could bias the model-data comparison.

The subarctic oceans contain large, shallow shelves where BD occurs. Seafloor $\delta^{15} \mathrm{~N}$ show higher values (6-10\%) towards the shallow shelves in the Bering Sea, Sea of Okhotsk, Baffin Bay, and Banks of Newfoundland, despite the fact that less enrichment during burial occurs on these shallow shelves (Robinson et al., 2012). The model experiment with the largest net fractionation factor for $\mathrm{BD}\left(\varepsilon_{\mathrm{BD}}=4 \%\right.$ ) best reproduces the observational trends of high seafloor $\delta^{15} \mathrm{~N}$ in these areas (Fig. 4), although values are still slightly underestimated. The other model experiments with smaller fractionation factors produced too low $\delta^{15} \mathrm{~N}$ throughout this region. Some of the bias in this region may also be due to the shallow continental shelves that are not fully resolved in MOBI, nor the small-scale processes that take place on them. This could significantly affect surface $\mathrm{NO}_{3}^{-}$utilization patterns, and thus seafloor $\delta^{15} \mathrm{~N}$. Future model versions with higher vertical resolution will evaluate this potential model bias. Nevertheless, this model-data comparison supports the view of net fractionation factors for BD to be $\geq 4 \%$, at least in the shallow subarctic ocean.

\subsubsection{Water column $\delta^{15} \mathrm{NO}_{3}^{-}$}

The global ocean mean $\delta^{15} \mathrm{NO}_{3}^{-}$is determined by the rates and isotope effects of the source and sink terms of the fixed$\mathrm{N}$ budget: $\mathrm{N}_{2}$ fixation, WCD, and BD. $\mathrm{N}_{2}$ fixation provides the ocean with ${ }^{15} \mathrm{~N}$-depleted nitrogen $\left(\delta^{15} \mathrm{~N}_{\mathrm{NFix}}=-1.5 \%\right.$ o). $\mathrm{N}$-loss processes, on the other hand, preferentially consume this ${ }^{15} \mathrm{~N}$-depleted nitrogen, leaving the global mean nitrate pool enriched in ${ }^{15} \mathrm{~N}$ (global mean $\delta^{15} \mathrm{NO}_{3}^{-}=\sim 5.5 \%$ ). The average net fractionation that occurs during total $\mathrm{N}$-loss determines how high the global mean $\delta^{15} \mathrm{NO}_{3}^{-}$will be relative to the ${ }^{15} \mathrm{~N}$-depleted nitrogen source from $\mathrm{N}_{2}$ fixation. We focus on two isotope effects with high uncertainty in this study: (i) OMZ nitrate utilization and dilution impacts on the isotope effect of WCD and (ii) the net fractionation factor associated with $\mathrm{BD}$.

\section{OMZ nitrate utilization and dilution isotope effect}

The elevated $\delta^{15} \mathrm{NO}_{3}^{-}$signature produced in suboxic zones depends on the level of nitrate utilization there. Utilization is determined by the balance between consumption by denitrification and replenishment by circulation and mixing. This balance determines the average $\delta^{15} \mathrm{NO}_{3}^{-}$value that denitrifiers consume and convert to $\mathrm{N}_{2}$ gas. The dilution effect takes into account that $\delta^{15} \mathrm{NO}_{3}^{-}$will be weighted towards the water parcel with higher nitrate when mixing occurs (Deutsch et al., 2004). For example, if the nitrate concentration in the suboxic zone is only half of the nitrate concentration in surrounding oxic waters, the $\delta^{15} \mathrm{NO}_{3}^{-}$signature of the oxic water will have twice the influence on total $\delta^{15} \mathrm{NO}_{3}^{-}$of these water masses if they mix together. Note that the dilution effect is inherently simulated in the physical circulation model.

High levels of nitrate utilization reduce the influence of the isotope effect of WCD on global mean $\delta^{15} \mathrm{NO}_{3}^{-}$. As average $\delta^{15} \mathrm{NO}_{3}^{-}$increases in suboxic zones as denitrification occurs, the nitrate removed then becomes more ${ }^{15} \mathrm{~N}$-enriched. The influence of the isotope effect of WCD on global mean $\delta^{15} \mathrm{NO}_{3}^{-}$is reduced when the removed nitrogen has a higher $\delta^{15} \mathrm{~N}$ signature that is closer to global mean $\delta^{15} \mathrm{NO}_{3}^{-}$.

For example, imagine a situation with high nitrate utilization in which the average $\delta^{15} \mathrm{NO}_{3}^{-}$value in the suboxic zone was $30.5 \%$ (instead of $\sim 12-15 \%$ o in the real ocean). The nitrogen removed would then have an isotopic signature $25 \%$ o depleted relative to this value, which would be equal to the global mean $\left(\delta^{15} \mathrm{~N}_{\text {removed }}=5.5 \%\right.$ ). In this case, it would have no influence on global mean $\delta^{15} \mathrm{NO}_{3}^{-}$, even though denitrification is still fractionating the nitrogen isotopes. Thus, as nitrate utilization increases the $\delta^{15} \mathrm{NO}_{3}^{-}$signature of the suboxic zone, it reduces the influence of WCD on global mean $\delta^{15} \mathrm{NO}_{3}^{-}$.

Experiments with high nitrate utilization in the suboxic zone require less NFix relative to WCD, and thus lower ratios of BD: WCD, to maintain global mean $\delta^{15} \mathrm{NO}_{3}^{-}$with a balance fixed-N budget. The nitrate utilization effect alone (varying limWCD) required $\mathrm{BD}: \mathrm{WCD}$ ratios that varied by nearly a factor of 2 in our range of sensitivity experiments (Table 2). BD is needed in the model to stimulate additional $\mathrm{N}_{2}$ fixation to balance global mean $\delta^{15} \mathrm{NO}_{3}^{-}$to the observed level. When nitrate utilization is high, the influence of the isotope effect of WCD is reduced and therefore less $\mathrm{BD}$, and lower $\mathrm{BD}: \mathrm{WCD}$ ratios, are required to balance global mean $\delta^{15} \mathrm{NO}_{3}^{-}$.

The model experiment that best reproduces nitrate and $\delta^{15} \mathrm{NO}_{3}^{-}$observations in the suboxic zone is limWCD $=32$ (Table 2, Fig. 5). It gives a good agreement with the amount of nitrate drawdown, as well as the slope of the increasing $\delta^{15} \mathrm{NO}_{3}^{-}$as nitrate is consumed according to off-shelf observations in suboxic zones. The experiments with higher levels of nitrate utilization ( $\operatorname{limWCD}=20,26)$ show too much nitrate consumption there. Due to deficiencies in the 


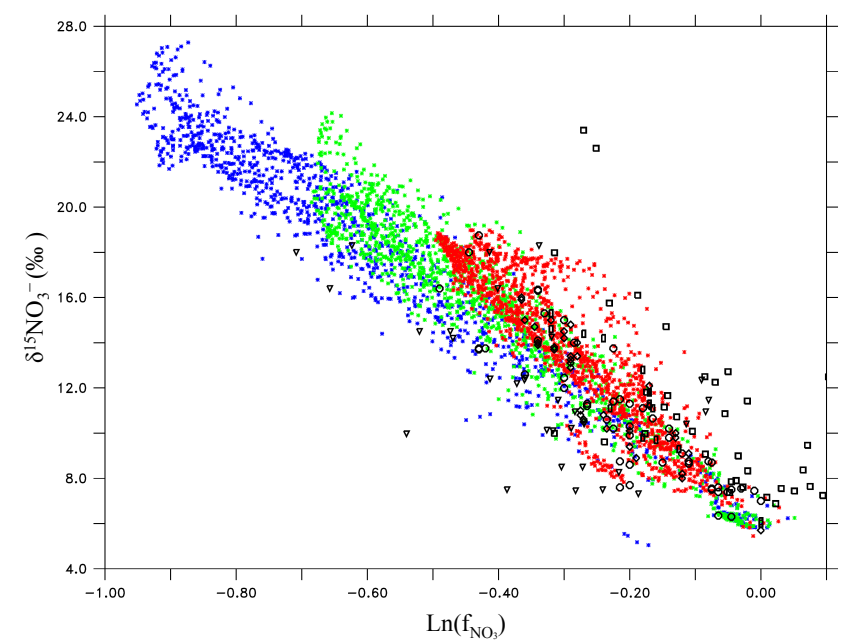

Fig. 5. Annual mean $\delta^{15} \mathrm{NO}_{3}^{-}$versus expected nitrate $\left(f_{\mathrm{NO}_{3}}\right)$ shows the increase of $\delta^{15} \mathrm{NO}_{3}^{-}$as $\mathrm{NO}_{3}^{-}$is consumed in suboxic zones $\left(\mathrm{O}_{2}<10 \mu \mathrm{M}\right)$ from the isotope effect of water column N-loss in $\lim W C D=20$ (blue), $\lim W C D=26$ (green), $\lim W C D=32$ (red) and observations (black) from Cline and Kaplan (1975) ([]), Altabet et al. (1995) ( $\Delta)$, Brandes et al. (1998) $(\diamond)$, Voss et al. (2001) (o), and Somes et al. (2010b) ( $\square$ ). Note $\varepsilon_{\mathrm{BD}}=0 \%$ or for the model experiments shown here. Expected nitrate is determined to be at the elemental ratio $15 \cdot \mathrm{PO}_{4}^{3-}$ in the model based on experiments where WCD was switched off (not shown), which is in agreement with the expected nitrate calculation from Voss et al. (2001) based on nitratedensity isopycnals. Observations near the seafloor are excluded to avoid any impact from benthic denitrification.

simulated suboxic zones, it still cannot be confirmed if the balance between nitrate consumption and replenishment is completely consistent with suboxic zones in the real ocean and the $\lim W C D=32$ experiment. However, the high sensitivity of estimated rates of NFix and denitrification in our model experiments that test different levels of nitrate utilization suggests nitrate utilization plays an important role in global nitrogen isotope cycling. This highlights the need for higher resolution models that fully resolve all of the ventilation pathways (e.g., coastal undercurrents and eddies) of suboxic zones.

\section{Isotope effect of benthic denitrification}

Recent studies (Lehmann et al., 2007; Granger et al., 2011; Alkhatib et al., 2012) have suggested a higher net fractionation factor associated with $\mathrm{BD}\left(\varepsilon_{\mathrm{BD}}=4-8 \%\right)$ compared to previous estimates $\left(\varepsilon_{\mathrm{BD}}=1-3 \%\right.$ ) (Brandes and Devol, 2002; Lehmann et al., 2004). They suggest BD should have a much higher net fractionation factor due to the measured high $\delta^{15} \mathrm{NH}_{4}^{+}$that is presumably released from the sediments where BD occurs. They propose this signal is due to fractionation during the nitrification-denitrification loop in the sediments. If this high net fractionation factor is indeed cor- rect on a global scale, higher $\mathrm{BD}$ : WCD ratios would be required to balance the nitrogen isotope budget because additional $\mathrm{N}_{2}$ fixation would be needed to balance this "extra" ${ }^{15} \mathrm{~N}$-enriched nitrogen produced in the sediments where BD occurs. However, ammonium efflux from the sediments is generally much higher on shallow shelves compared to deep ocean seafloor (Bohlen et al., 2012), suggesting that the global average fractionation of $\mathrm{BD}$ is likely lower than these estimates (Lehmann et al., 2007). We test the sensitivity of this effect by running experiments with $\varepsilon_{\mathrm{BD}}$ set to 0,2 , and $4 \%$, while holding the limWCD parameter constant at 32 , which best represented $\delta^{15} \mathrm{NO}_{3}^{-}$observations in the suboxic zone.

The range of relative rates of $\mathrm{BD}: \mathrm{WCD}$ required to closely reproduce observed global mean $\delta^{15} \mathrm{NO}_{3}^{-}$for our sensitivity experiments $\left(\varepsilon_{\mathrm{BD}}=0-4 \%\right.$ ) varied from 1.4 to 3.5 (Table 2). This large range is mostly caused by variations in $\mathrm{BD}$ rates and suggests that a misrepresentation of this isotope effect can significantly bias the estimate for the BD: WCD ratio. The lack of water column $\delta^{15} \mathrm{NH}_{4}^{+}$measurements overlying sites of $\mathrm{BD}$, most notably in the deep ocean, makes it difficult to constrain the global response at this time. We note our data-model analysis with the seafloor $\delta^{15} \mathrm{~N}$ database supports the high estimates for the net fractionation factor of $\mathrm{BD}$ $\left(\varepsilon_{\mathrm{BD}} \geq 4 \%\right.$ o $)$ in the subarctic ocean that contains many shallow shelves where BD rates are high (Table 3 and Figs. 3, 4). Riverine $\delta^{15} \mathrm{~N}$ input is not included in this model, which can also influence some coastal settings with the input of $\delta^{15} \mathrm{~N}$ between 1 and 5\%o (Brandes and Devol, 2002). Since riverine $\mathrm{N}$ input $\left(\sim 25 \mathrm{Tg} \mathrm{Nyr}^{-1}\right)$ is relatively small compared to $\mathrm{BD}\left(\geq 150 \mathrm{Tg} \mathrm{N} \mathrm{yr}^{-1}\right)$ and introduces $\delta^{15} \mathrm{~N}$ near the oceanic average, it is unlikely to have a large global impact on the ratio of $\mathrm{BD}: \mathrm{WCD}$ in the pre-industrial ocean, but still may bias the model-data comparison at some locations.

\section{Discussion}

Our nitrogen isotope sensitivity experiments produce a large range of potential Nfix and denitrification rates that vary by over a factor of 2 (Table 2, Figs. 2, 6). We show that different nitrogen isotope parameters chosen for the isotope effects of WCD and BD significantly affect the estimates of the BD:WCD ratio needed to satisfy the global mean $\delta^{15} \mathrm{NO}_{3}^{-}$constraint. This is in general agreement with previous box model studies that also estimate a large range from 1 to 3.7 (Brandes and Devol, 2002; Deutsch et al., 2004; Altabet, 2007; Eugster and Gruber, 2012), when different isotope effects for denitrification were used in their respective models. These results show the importance of correctly modeling each isotope effect to simulate the balance of Nfix and denitrification that determines the observed global mean $\delta^{15} \mathrm{NO}_{3}^{-}$.

We create another global one-box $\delta^{15} \mathrm{NO}_{3}^{-}$model (called $0 \mathrm{D}$ in the following) that includes $\mathrm{N}_{2}$ fixation, $\mathrm{WCD}$, and $\mathrm{BD}$ 

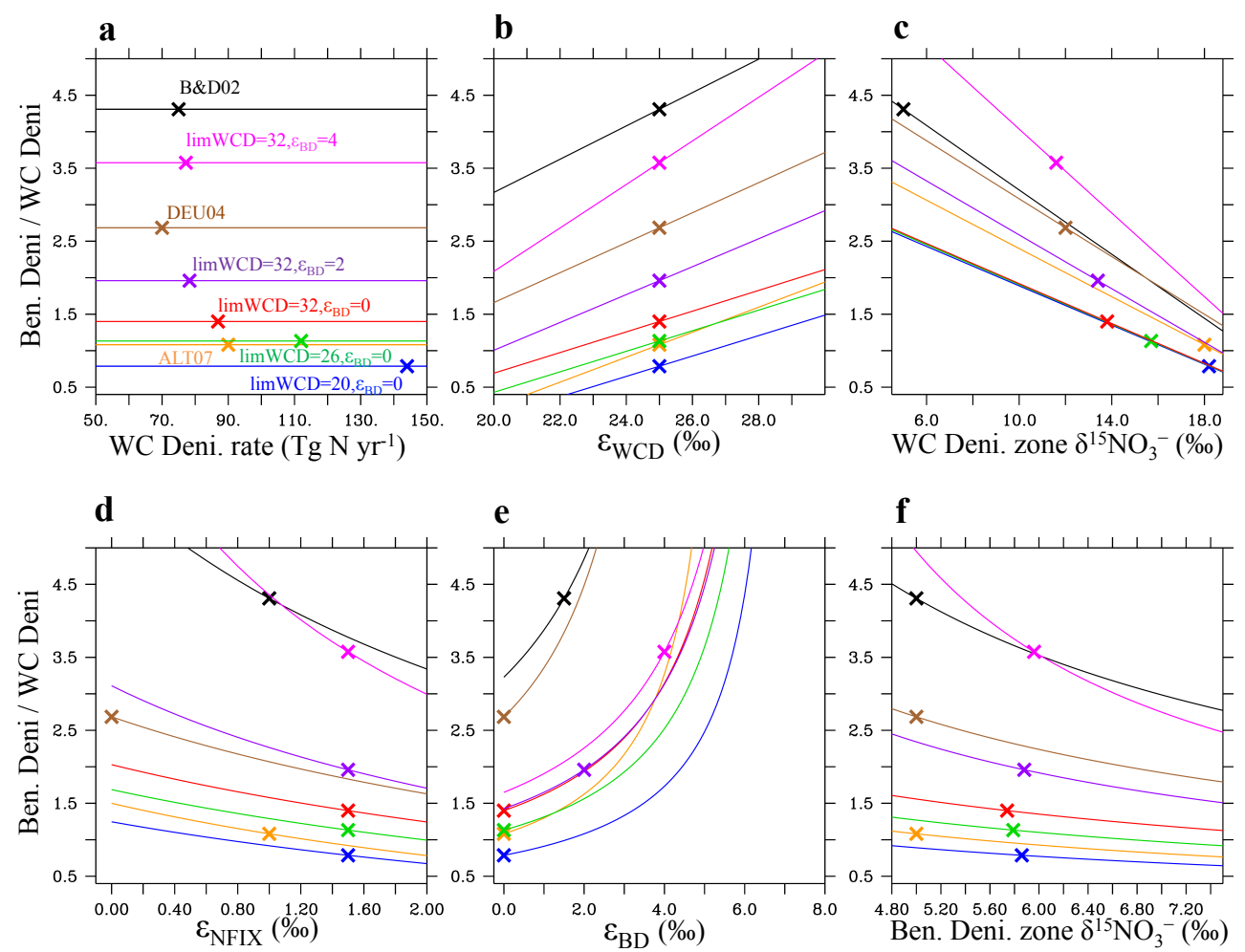

\section{$\mathbf{f}$}

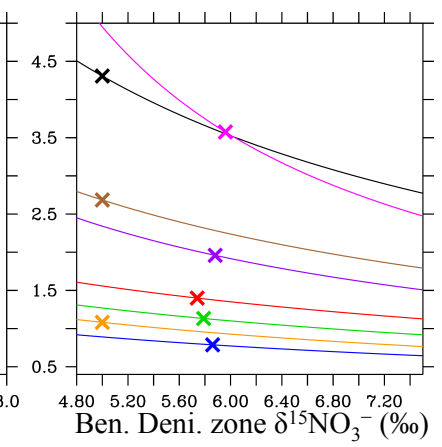

Fig. 6. Results of the one-box $\delta^{15} \mathrm{NO}_{3}^{-}$model with different nitrogen isotope parameter settings according to previous configurations (Brandes and Devol, 2002; Deutsch et al., 2004; Altabet, 2007) and this study (Table 4). Each panel shows the sensitivity of one parameter on the ratio of benthic denitrification to water column denitrification (BD : WCD) needed to achieve observed global mean $\delta^{15} \mathrm{NO}_{3}^{-}$in a steady-state scenario while all other parameters are held constant: (a) WCD rate, (b) WCD fractionation factor $\left(\varepsilon_{\mathrm{WCD}}\right)$, (c) average $\delta^{15} \mathrm{NO}_{3}^{-}$value where WCD occurs, (d) $\mathrm{N}_{2}$ fixation fractionation factor $\left(\varepsilon_{\mathrm{NFix}}\right)$, (e) benthic denitrification fractionation factor $\left(\varepsilon_{\mathrm{BD}}\right)$, and (f) average $\delta^{15} \mathrm{NO}_{3}^{-}$value where benthic denitrification occurs. Note $\varepsilon_{\text {NFix }}$ makes diazotroph biomass depleted in $\delta^{15} \mathrm{~N}$ by its associated value. The crosses (X) show the parameter chosen for each reported model configuration and denotes the BD to WCD ratio of the previous studies as well as coupled three-dimensional experiments from this study.

to perform a more thorough sensitivity analysis of the key nitrogen isotope parameters. The OD model is designed to calculate the required ratio of $\mathrm{BD}$ to $\mathrm{WCD}$ to maintain the observed global mean $\delta^{15} \mathrm{NO}_{3}^{-}$in a steady-state pre-industrial ocean. The OD model then calculates the BD to WCD ratio required for different nitrogen isotope parameters chosen from previous model studies and the sensitivity experiments from this study (Table 4) using Eq. (A12).

The OD model used here accurately reproduces the reported $\mathrm{BD}$ : WCD ratios of the various model configurations used in this study as well as previous studies despite the large range of model design and parameter selections (Table 4). This suggests our OD model may be reliable to estimate the sensitivity of the different nitrogen isotope parameters in a steady-state scenario. It shows that the BD: WCD ratio needed to match global mean $\delta^{15} \mathrm{NO}_{3}^{-}$is very sensitive to the level of OMZ nitrate utilization that determines WCD zone $\delta^{15} \mathrm{NO}_{3}^{-}$and net fractionation factor chosen for BD, as well as other parameters (Fig. 6). The range of uncertainty for these two effects can alone account for a large range of estimates for BD (100-280 $\mathrm{Tg} \mathrm{N} \mathrm{yr}^{-1}$ ) from previous nitrogen isotope models (Brandes and Devol, 2002; Deutsch et al., 2004; Altabet, 2007; Eugster and Gruber, 2012).

The large uncertainty associated with the net fractionation factor of $\mathrm{BD}$ adds further difficulties to constraining the $\mathrm{BD}$ : WCD ratio using global mean $\delta^{15} \mathrm{NO}_{3}^{-}$. Our experiments show that increasing this factor from 0 to $4 \%$ requires almost triple the BD rate needed to maintain the global mean $\delta^{15} \mathrm{NO}_{3}$ at observed levels. Recent estimates suggest that the net fractionation factor may be even higher (4-8\%o) due to fractionation within the nitrification-denitrification loop in the sediments (Granger et al., 2011; Alkhatib et al., 2012). If these high-end estimates are validated on a global scale, this could require larger $\mathrm{BD}$ : WCD ratios than our largest value simulated here $(>3.5)$. An experiment testing $\varepsilon_{\mathrm{BD}}=6 \%$ o in $\mathrm{MOBI}$ required too high $\mathrm{BD}$ rates to achieve a balanced global $\mathrm{NO}_{3}^{-}$inventory at the modern level in the model and thus is not included here. However, Lehmann et al. (2007) show that shallow regions have a higher net fractionation compared to deep ocean sites and the global average net 
Table 4. $\delta^{15} \mathrm{~N}$ box model parameter list.

\begin{tabular}{|c|c|c|c|c|c|c|c|c|}
\hline & $\varepsilon_{\text {NFix }}(\% o)$ & $\begin{array}{c}\text { WCD rate } \\
\left(\mathrm{TgN}^{-1}\right)\end{array}$ & $\begin{array}{c}\varepsilon_{\mathrm{WCD}} \\
(\%)\end{array}$ & $\begin{array}{c}\text { WCD zone } \\
\delta^{15} \mathrm{NO}_{3}^{-}(\% \circ)\end{array}$ & $\begin{array}{l}\varepsilon_{\mathrm{BD}} \\
(\%)\end{array}$ & $\begin{array}{c}\text { BD zone } \\
\delta^{15} \mathrm{NO}_{3}^{-}(\% \circ)\end{array}$ & $\begin{array}{l}\text { BD : WCD } \\
\text { (0D model) }\end{array}$ & $\begin{array}{l}\text { BD : WCD } \\
\text { (reported) }\end{array}$ \\
\hline $\mathrm{B} \& \mathrm{D} 02^{1}$ & 1 & 75 & 25 & 5 & 1.5 & 5 & 4.31 & 3.73 \\
\hline DEU04 & 0 & 70 & 25 & 12 & 0 & 5 & 2.69 & 2.71 \\
\hline ALT07 $^{2}$ & 1 & 90 & 25 & 18 & 0 & 5 & 1.01 & $\sim 1.00$ \\
\hline $\lim W C D=20, \varepsilon_{\mathrm{BD}}=0$ & 1.5 & 144 & 25 & 18.2 & 0 & 5.86 & 0.787 & 0.757 \\
\hline $\operatorname{limWCD}=26, \varepsilon_{\mathrm{BD}}=0$ & 1.5 & 112 & 25 & 15.7 & 0 & 5.79 & 1.13 & 1.13 \\
\hline $\lim W C D=32, \varepsilon_{\mathrm{BD}}=0$ & 1.5 & 87.6 & 25 & 13.8 & 0 & 5.74 & 1.40 & 1.39 \\
\hline $\operatorname{limWCD}=32, \varepsilon_{\mathrm{BD}}=2$ & 1.5 & 78.3 & 25 & 13.4 & 2 & 5.88 & 1.96 & 1.96 \\
\hline $\lim \mathrm{WCD}=32, \varepsilon_{\mathrm{BD}}=4$ & 1.5 & 77.0 & 25 & 11.6 & 4 & 5.96 & 3.58 & 3.53 \\
\hline
\end{tabular}

${ }^{1}$ Brandes and Devol (2002) reported ratio also included isotope effects from atmospheric $\mathrm{N}$ deposition, river input, and sediment burial, which are excluded in the 0D one-box model calculation to maintain consistency with the other model configurations. These processes slightly reduce the BD:WCD ratio and suggests the other model estimates may be slightly overestimating BD: WCD as well.

${ }^{2}$ Altabet (2007) used a combination of reducing the fractionation factor of WCD (to account for circulation effects not included in the one-box model) and increasing WCD zone $\delta^{15} \mathrm{NO}_{3}^{-}$so the $\delta^{15} \mathrm{~N}$ value of nitrogen removed was $-7 \%$. We leave $\varepsilon_{\mathrm{WCD}}$ at $25 \%$ and increase the WCD zone $\delta^{15} \mathrm{NO}_{3}^{-}$to $18 \%$ to achieve his suggested $\delta^{15} \mathrm{~N}$ value of $-7 \%$ for nitrogen removal.

fractionation is likely closer to $4 \%$. Our $0 \mathrm{D}$ experiments also show that no model configuration is able to support a global net fractionation factor for $\mathrm{BD}$ greater than $6 \%$ and predict $\mathrm{BD}: \mathrm{WCD}$ ratios in range of observational estimates $(\mathrm{BD}: \mathrm{WCD} \leq 4)$ (Fig. 6e).

MOBI experiments \#4 and \#5 predict BD rates on the continental shelves (60 and $108 \mathrm{Tg} \mathrm{Nyr}^{-1}$, respectively) that are on the low-end of most recent estimates (80$125 \mathrm{Tg} \mathrm{N} \mathrm{yr}^{-1}$ ) (Bianchi et al., 2012; Bohlen et al., 2012; DeVries et al., 2013) and much lower than another estimate of $250 \mathrm{Tg} \mathrm{Nyr}^{-1}$ (Seitzinger et al., 2006). If much more $\mathrm{BD}$ is occurring on the continental shelves than predicted by MOBI, this can impact the isotope effect of BD because $\delta^{15} \mathrm{NO}_{3}^{-}$of bottom water on the shelves is on average $\sim 1.5 \%$ higher compared to the deep ocean in the model due to its close proximity to surface $\mathrm{NO}_{3}^{-}$utilization. This would lead to higher values for the BD zone $\delta^{15} \mathrm{NO}_{3}^{-}$parameter, which would require lower BD: WCD ratios (Fig. 6f). Note that this parameter has a smaller effect on BD: WCD ratios compared to the others (Fig. 6), suggesting that its uncertainty is likely lower than the other isotope parameters (e.g., net fractionation factor of BD).

The level of nitrate utilization in OMZs has a strong influence on the isotope effect of WCD. It determines the $\delta^{15} \mathrm{NO}_{3}^{-}$ value in WCD zones that is consumed by denitrifiers. Figure $6 \mathrm{c}$ shows the range of $\mathrm{BD}: \mathrm{WCD}$ ratios required for given $\delta^{15} \mathrm{NO}_{3}^{-}$signatures in the WCD zones for all experiments. These idealized experiments using the parameter settings of $\lim W C D=20,26$, and 32 (when $\varepsilon_{\mathrm{BD}}=0$ ) show that the different level of nitrate utilization, and its effect on $\delta^{15} \mathrm{NO}_{3}^{-}$ in the WCD zone, is causing the range of $\mathrm{BD}$ : WCD ratios from 0.8 to 1.4 in these experiments. This demonstrates that if the isotope effect of WCD is not modeled accurately, it can lead to large biases of the estimates for BD: WCD.
For example, Brandes and Devol (2002) did not account for the locally high $\delta^{15} \mathrm{NO}_{3}^{-}$of WCD zones in their one-box model (Fig. 6c). The $\delta^{15} \mathrm{NO}_{3}^{-}$removed during WCD is thus much more ${ }^{15} \mathrm{~N}$-depleted compared to the other models that take into account nitrate utilization in the suboxic zone. This increases the isotope effect of WCD in the Brandes and Devel (2002) model configuration, and it thus needs more $\mathrm{N}_{2}$ fixation to maintain global mean $\delta^{15} \mathrm{NO}_{3}^{-}$, which is achieved by imposing a higher $\mathrm{BD}$ : WCD ratio. If they had accounted for a more realistic suboxic-zone $\delta^{15} \mathrm{NO}_{3}^{-}$signature in the range of the other model configurations, our 0D model suggests their estimate for BD: WCD could have been nearly a factor of 2 lower (Fig. 6c).

Our MOBI experiment \#5 $\left(\operatorname{limWCD}=32, \varepsilon_{\mathrm{BD}}=4\right)$ is in general agreement with the final results of Brandes and Devol (2002), suggesting a relatively high rate of BD, despite that the $\delta^{15} \mathrm{~N}$ model configuration for the isotope effects of water column and BD is much different (Table 4). This suggests that even though the simple one-box model of Brandes and Devol (2002) was able to reach a similar result, it was due to a different combination of isotope effects that are difficult to constrain in a one-box model. The fact that MOBI results are directly comparable to $\delta^{15} \mathrm{~N}$ observations in regions where denitrification occurs in the water column and sediments allows better validation of the various isotope effects.

The average level of nitrate utilization throughout the ocean's prominent suboxic zones remains difficult to assess. While studies in the eastern tropical North Pacific (ETNP) and Arabian Sea OMZs do not typically show nitrate depleted below half of its expected value (Brandes et al., 1998; Voss et al., 2001), recent results from the ETSP suboxic zone show more than two-thirds of the expected nitrate was consumed with a much smaller fractionation factor (Ryabenko et al., 2012). They note large rates of BD occurring within close proximity to WCD were likely contributing to this larger 
nitrate deficit and reduced fractionation. Furthermore, evidence from an eddy entraining suboxic water from the ETSP OMZ showed an even larger level of nitrate utilization as it moved offshore (Altabet et al., 2012). These results suggests that an average level of nitrate utilization in the global suboxic zones may be higher than off-shore observations from the Arabian Sea and ETNP included in Fig. 4. Since MOBI does not incorporate these specific isotope effects inferred from observations in the ETSP OMZ, the model may overestimate the global net WCD isotope effect and thus $\mathrm{BD}: \mathrm{WCD}$ ratios in the ocean (Altabet, 2007).

The 6-box model of Deutsch et al. (2004) accounts for local nitrate utilization with a designated suboxic box, but still estimates a higher BD : WCD ratio (2.69) compared to the results from our MOBI experiment in which the fractionation factor for $\mathrm{BD}$ was also set to $0 \%$ ( $\mathrm{BD}: \mathrm{WCD}=1.4)$. The most significant difference between the Deutsch et al. (2004) and the other model configurations is the isotope effect of $\mathrm{N}_{2}$ fixation. Deutsch et al. (2004) chose a $\delta^{15} \mathrm{~N}_{\mathrm{NFix}}$ signature of $0 \%$, while all other models selected between -1 and $-1.5 \%$. If the Deutsch et al. (2004) study would have chosen the same value as here $\left(\delta^{15} \mathrm{~N}_{\mathrm{NFix}}=-1.5 \%\right.$ ) , our $0 \mathrm{D}$ model suggests this would decrease their estimated $\mathrm{BD}: \mathrm{WCD}$ ratio from 2.69 to 1.83 , which would then be more consistent with the results from MOBI. This shows that even small differences $\left(<2 \%\right.$ ) for the isotope effect of $\mathrm{N}_{2}$ fixation can alter the ratio of $\mathrm{BD}: \mathrm{WCD}$ by $30 \%$ or even more depending on the model configuration used (Fig. 6d).

The MOBI experiments that most closely reproduce seafloor $\delta^{15} \mathrm{~N}$ observations are experiments \#4 and \#5 ( $\lim W C D=32, \varepsilon_{\mathrm{BD}}=2$ and 4 ), with $\varepsilon_{\mathrm{BD}}=2$ producing slightly better correlation and root mean squared error statistics. (Table 2). They predict a range of rates for $\mathrm{N}_{2}$ fixation, WCD, and BD between 225-342, 76, and 149-267 $\mathrm{Tg} \mathrm{N} \mathrm{yr}^{-1}$, respectively. These experiments produce a large range of $\mathrm{BD}$ : WCD ratios from 2 to 3.5 and highlight the high sensitivity of the $\mathrm{BD}$ : WCD ratio to the net fractionation factor of $\mathrm{BD}$. Although the average level of nitrate utilization in the suboxic zones is uncertain, our experiments using limWCD $=32$ best represent observations from the ETNP and Arabian Sea. Assuming this range for nitrogen isotope parameters, our model estimates a potential range for $\mathrm{BD}$ : WCD of 2.0-3.5.

Our model experiments are in general agreement with a recent 3D inverse model that included nitrogen isotopes to constrain marine denitrification rates (DeVries et al., 2013). They similarly show a high sensitivity to the $\mathrm{NO}_{3}^{-}$utilization in the suboxic zone and fractionation factor assumed for BD. However, they estimate lower ratios of BD: WCD from 1.3 to 2.3 compared to our results with MOBI. The main reasons for this discrepancy are likely that DeVries et al. (2013) assumed a slightly higher level of nitrate utilization in the suboxic zones and lower values for $\varepsilon_{\mathrm{BD}}=0-3 \%$, whereas our high-end estimate for $\mathrm{BD}: \mathrm{WCD}=3.5$ is due to using $\varepsilon_{\mathrm{BD}}=4 \%$. The high sensitivity to these parameters empha- sizes the need to better understand and quantify them in future studies.

\section{Conclusions}

Our study uses water column $\delta^{15} \mathrm{NO}_{3}^{-}$and seafloor $\delta^{15} \mathrm{~N}$ observations to constrain the rates of $\mathrm{N}_{2}$ fixation, WCD, and $\mathrm{BD}$ in the global ocean. The uncertainty associated with isotope effects of denitrification in the water column and sediments makes it difficult to constrain $\mathrm{N}_{2}$ fixation and total denitrification rates. Previous box model studies using $\delta^{15} \mathrm{~N}$ have estimated a large range for the ratio of $\mathrm{BD}: \mathrm{WCD}$ from 1 to 3.7 (Brandes and Devol, 2002; Deutsch et al., 2004; Altabet, 2007; Eugster and Gruber, 2012). Here we used a set of experiments with a global coupled three-dimensional circulation-biogeochemistry-isotope model (MOBI) and a one-box model to show that nitrate utilization in the suboxic zone and the net fractionation factor of $\mathrm{BD}$, both of which are not well constrained by observations, can lead to rates of BD that vary by over a factor of 2 if not modeled correctly.

With our global coupled three-dimensional model, we are able to compare $\delta^{15} \mathrm{~N}$ observations in the water column and seafloor in the regions where denitrification occurs to constrain the nitrogen isotope parameters in the model. This highlights the importance of using models that can resolve all of the locally important nitrogen isotope effects that affect $\delta^{15} \mathrm{~N}$ in denitrification zones. The model experiments that best reproduce $\delta^{15} \mathrm{~N}$ observations in the water column and sediments estimate the rates of $\mathrm{N}_{2}$ fixation, WCD, and BD in the ranges of $195-350,65-80$, and $130-270 \mathrm{Tg} \mathrm{N} \mathrm{yr}^{-1}$, respectively, assuming a balanced fixed-N budget in the preindustrial ocean. Although uncertainties still exist, this model result suggests that $\mathrm{N}_{2}$ fixation is occurring at much greater rates than previously estimated, and the residence time for oceanic fixed nitrogen is between $\sim 1500$ and $3000 \mathrm{yr}$.

\section{Appendix A}

\section{Nitrogen isotope model description}

\section{A1 Fractionation equation}

Fractionation is calculated using kinetic fractionation (Mariotti et al., 1981):

$$
\frac{{ }^{15} \mathrm{~N}_{\text {pro }}}{{ }^{14} \mathrm{~N}_{\text {pro }}}=\alpha \frac{{ }^{15} \mathrm{~N}_{\mathrm{sub}}}{{ }^{14} \mathrm{~N}_{\mathrm{sub}}},
$$

where $\alpha$ is the kinetic fractionation factor associated with the process and the $\mathrm{N}_{\text {pro }}$ and $\mathrm{N}_{\text {sub }}$ refer to the nitrogen of the product and substrate of the reaction, respectively. In the model, we include ${ }^{15} \mathrm{~N}$ as the prognostic variable instead of the ratio ${ }^{15} \mathrm{~N} /{ }^{14} \mathrm{~N}$. The ${ }^{15} \mathrm{~N}$ equations are embedded within the marine ecosystem model that calculates total $\mathrm{N}$ 
$\left({ }^{T} \mathrm{~N}={ }^{15} \mathrm{~N}+{ }^{14} \mathrm{~N}\right)$. Solving Eq. (A1) for ${ }^{15} \mathrm{~N}_{\text {pro }}$ with respect to ${ }^{T} \mathrm{~N}_{\text {pro }}$ yields

${ }^{15} \mathrm{~N}_{\text {pro }}=\frac{\alpha R_{\text {sub }}}{1+\alpha R_{\text {sub }}}{ }^{T} \mathrm{~N}_{\text {pro }}$,

where $R_{\text {sub }}$ is the isotopic ratio ${ }^{15} \mathrm{~N} /{ }^{14} \mathrm{~N}$ of the substrate of the reaction.

This equation can be equivalently expressed in the commonly used delta (" $\delta$ ") notation by applying the relation (Mariotti et al., 1981):

$\alpha=1-\varepsilon / 1000$,

which gives positive values for $\varepsilon$ with this definition. Eq. (A2) then becomes

${ }^{15} \mathrm{~N}_{\text {pro }}=\frac{\beta}{1+\beta}{ }^{T} \mathrm{~N}_{\text {pro }}$,

where $\beta=R_{\text {sub }}(1-\varepsilon / 1000)$ (Giraud et al., 2000), which is the nitrogen isotope equation coded into MOBI. Note we use a $R_{\text {std }}$ value of 1 so that ${ }^{14} \mathrm{~N}$ and ${ }^{15} \mathrm{~N}$ have concentrations of the same order of magnitude. This reduces the impact of numerical noise caused by the advection scheme on the $\delta^{15} \mathrm{~N}$ value. If the atmospheric $\mathrm{N}_{2}$ ratio was used $\left(R_{\text {std }}=0.0036765\right)$, the ${ }^{15} \mathrm{~N}$ concentration would be over two orders of magnitude smaller and be more susceptible to numerical noise, which produces erroneous $\delta^{15} \mathrm{~N}$ values. In the polar oceans $\left(>80^{\circ} \mathrm{N} / \mathrm{S}\right)$ where numerical noise is the highest in our global model, some model grid points still contain erroneous isotope values so this region is not included in the statistical analysis.

\section{A2 Coupled model equations}

The fractionation equation used for $\mathrm{NO}_{3}^{-}$consumption during phytoplankton uptake and WCD follows Eq. (A4) where $\beta=R_{\text {sub }}[1-\varepsilon \cdot(1-u) / u \cdot \ln (1-u) / 1000]$ and $u$ is the fraction of available total nitrate consumed during each time step. This fractionation equation is used to ensure that if a significant portion of the nitrate pool is consumed in one time step, mass balance of the different nitrogen isotope species is conserved. In the experiments here, we artificially limit WCD at high enough nitrate concentrations $(26-32 \mu \mathrm{M})$ so this term $[(1-u) / u \cdot \ln (1-u)]$ has a negligible effect for WCD in this study. Since zooplankton excretion and BD are parameterized in the model, the instantaneous fractionation equation is used (Eq. A4) with a given fractionation factor to mimic the net fractionation that occurs during the integrated reaction.

The full set of time-dependent equations for ${ }^{15} \mathrm{~N}$ that are embedded into the marine ecosystem biogeochemical model are as follows:

$$
\begin{aligned}
& \frac{\partial{ }^{15} \mathrm{NO}_{3}^{-}}{\partial t}=\left({ }^{T} R_{\mathrm{D}} \mu_{\mathrm{D}}^{*} \mathrm{D}+\frac{\beta_{\text {excr }}}{1+\beta_{\text {excr }}} \mu_{\mathrm{Z}}^{*} \mathrm{Z}+{ }^{T} R_{\mathrm{P}_{\mathrm{O}}} \mu_{\mathrm{P}_{\mathrm{O}}}^{*} \mathrm{P}_{\mathrm{O}}\right. \\
& +{ }^{T} R_{\mathrm{P}_{\text {Diaz }}} \mu_{\mathrm{P}_{\text {Diaz }}}^{*} \mathrm{P}_{\text {Diaz }}+{ }^{T} R_{\mathrm{P}_{\text {Diaz }}} \gamma \mathrm{GE}\left(\mathrm{P}_{\text {Diaz }}\right) \mathrm{Z} \\
& \left.-\frac{\beta_{\text {assim }}}{1+\beta_{\text {assim }}} J_{\mathrm{O}}^{*} \mathrm{P}_{\mathrm{O}}-\frac{\beta_{\text {assim }}}{1+\beta_{\text {assim }}} u_{\mathrm{NO}_{3}^{-}} J_{\text {Diaz }}^{*} \mathrm{P}_{\text {Diaz }}\right) \\
& \times\left[1-\frac{\beta_{\mathrm{WCD}}}{1+\beta_{\mathrm{WCD}}} 0.8 r_{\mathrm{O}: \mathrm{N}} \rho_{\mathrm{sox}}^{\mathrm{NO}_{3}^{-}} L_{\mathrm{lim} \mathrm{WCD}}\right] \\
& -\frac{\beta_{\mathrm{BD}}}{1+\beta_{\mathrm{BD}}} \alpha_{\mathrm{BD}} \mathrm{BD} \cdot L_{\mathrm{BD}} \\
& \frac{\partial^{15} \mathrm{~N}-\mathrm{P}_{\mathrm{O}}}{\partial t}=\frac{\beta_{\text {assim }}}{1+\beta_{\text {assim }}} J_{\mathrm{O}}^{*} \mathrm{P}_{\mathrm{O}}-{ }^{T} R_{\mathrm{P}_{\mathrm{O}}} \mu_{\mathrm{P}_{\mathrm{O}}}^{*} \mathrm{P}_{\mathrm{O}} \\
& -{ }^{T} R_{\mathrm{P}_{\mathrm{O}}} G\left(\mathrm{P}_{\mathrm{O}}\right) \mathrm{Z}-{ }^{T} R_{\mathrm{P}_{\mathrm{O}}} \nu_{\mathrm{P}_{\mathrm{O}}} \mathrm{P}_{\mathrm{O}}^{2} \\
& \frac{\partial^{15} \mathrm{~N}-\mathrm{P}_{\mathrm{Diaz}}}{\partial t}=\left(\frac{\beta_{\mathrm{assim}}}{1+\beta_{\mathrm{assim}}} u_{\mathrm{NO}_{3}^{-}}+\frac{\beta_{\mathrm{NFix}}}{1+\beta_{\mathrm{NFix}}}\left(1-u_{\mathrm{NO}_{3}^{-}}\right)\right) \\
& J_{\text {Diaz }}^{*} \mathrm{P}_{\text {Diaz }}-{ }^{T} R_{\mathrm{P}_{\text {Diaz }}} \mu_{\mathrm{P}_{\text {Diaz }}}^{*} \mathrm{P}_{\text {Diaz }} \\
& -{ }^{T} R_{\mathrm{P}_{\text {Diaz }}} G\left(\mathrm{P}_{\text {Diaz }}\right) \mathrm{Z}-{ }^{T} R_{\mathrm{P}_{\text {Diaz }}} \nu_{\mathrm{P}_{\text {Diaz }}} \mathrm{P}_{\text {Diaz }}^{2}, \\
& \frac{\partial{ }^{15} \mathrm{~N}-\mathrm{Z}}{\partial t}=\gamma\left[{ }^{T} R_{\mathrm{P}_{\mathrm{O}}} G\left(\mathrm{P}_{\mathrm{O}}\right)+{ }^{T} R_{\mathrm{P}_{\mathrm{Diaz}}} G\left(\mathrm{P}_{\mathrm{Diaz}}\right)\right] \mathrm{Z} \\
& -\frac{\beta_{\text {excr }}}{1+\beta_{\text {excr }}} \mu_{\mathrm{Z}}^{*} \mathrm{Z}-{ }^{T} R_{\mathrm{Z}} v_{\mathrm{Z}} \mathrm{Z}^{2} \text {, }
\end{aligned}
$$

and

$$
\begin{aligned}
\frac{\partial^{15} \mathrm{~N}-\mathrm{D}}{\partial t}= & (1-\gamma)\left[{ }^{T} R_{\mathrm{P}_{\mathrm{O}}} G\left(\mathrm{P}_{\mathrm{O}}\right)+{ }^{T} R_{\mathrm{P}_{\mathrm{Diaz}}} G\left(\mathrm{P}_{\mathrm{Diaz}}\right)\right] \mathrm{Z} \\
& -{ }^{T} R_{\mathrm{D}} \mu_{\mathrm{D}}^{*} \mathrm{D}+{ }^{T} R_{\mathrm{P}_{\mathrm{O}}} \nu_{\mathrm{P}_{\mathrm{O}}} \mathrm{P}_{\mathrm{O}}^{2}+{ }^{T} R_{\mathrm{P}_{\mathrm{Diaz}}} \nu_{\mathrm{P}_{\mathrm{Diaz}}} \mathrm{P}_{\mathrm{Diaz}}^{2} \\
& +{ }^{T} R_{\mathrm{Z}} v_{\mathrm{Z}} \mathrm{Z}^{2}-{ }^{T} R_{\mathrm{D}} w_{\mathrm{D}} \frac{\partial D}{\partial z}
\end{aligned}
$$

where ${ }^{T} R_{X}={ }^{15} \mathrm{~N}_{X} /\left({ }^{15} \mathrm{~N}_{X}+{ }^{14} \mathrm{~N}_{X}\right)$. Here it suffices to note that the equations for total nitrogen $\left({ }^{14} \mathrm{~N}+{ }^{15} \mathrm{~N}\right)$ are identical to the ones for ${ }^{15} \mathrm{~N}$, except that ${ }^{T} R_{X}=\beta_{X} /\left(1+\beta_{X}\right)=1$ in the total nitrogen equations. The parameter list is given in Table B1.

\section{A3 0D model}

The one-box $\delta^{15} \mathrm{NO}_{3}^{-}$model assumes the fixed nitrogen inventory and the nitrogen isotope inventory are both in steady state. This yields the following equations for total fixed nitrogen and $\delta^{15} \mathrm{NO}_{3}^{-}$:

$\mathrm{NFix}=\mathrm{WCD}+\mathrm{BD}$

and

$$
\begin{aligned}
\mathrm{NFix} \cdot\left(\frac{\beta}{1+\beta}\right)_{\mathrm{NFix}}= & \mathrm{WCD} \cdot\left(\frac{\beta}{1+\beta}\right)_{\mathrm{WCD}} \\
& +\mathrm{BD} \cdot\left(\frac{\beta}{1+\beta}\right)_{\mathrm{BD}}
\end{aligned}
$$


Table B1. Marine ecosystem-biogeochemical parameter list*.

\begin{tabular}{llrl}
\hline Parameter & Symbol & Value & Units \\
\hline & \multicolumn{1}{c}{ Phytoplankton $\left(\mathrm{P}_{\mathrm{O}}, \mathrm{P}_{\mathrm{D}}\right)$ coefficients } & \\
Initial slope of P-I curve & $\alpha$ & 0.1 & $\left(\mathrm{~W} \mathrm{~m}^{-2}\right)^{-1} \mathrm{~d}^{-1}$ \\
Photosynthetically active radiation & PAR & 0.43 & \\
Light attenuation in water & $k_{\mathrm{W}}$ & 0.04 & $\mathrm{~m}^{-1}$ \\
Light attenuation through phytoplankton & $k_{\mathrm{c}}$ & 0.03 & $\mathrm{~m}^{-1}\left(\mathrm{mmol} \mathrm{m}^{-3}\right)-1$ \\
Light attenuation through sea ice & $k_{\mathrm{i}}$ & 5 & $\mathrm{~m}^{-1}$ \\
Half-saturation constant for N uptake & $k_{\mathrm{N}}$ & 0.7 & $\mathrm{mmol} \mathrm{m}^{-3}$ \\
Phytoplankton specific mortality rate & $\nu_{\mathrm{P}_{\mathrm{O}}}$ & 0.025 & $\mathrm{~d}^{-1}$ \\
Maximum growth rate (at $\left.0{ }^{\circ} \mathrm{C}\right)$ & $a_{0}$ & 0.35 & $\mathrm{~d}^{-1}$ \\
Phytoplankton fast-recycling rate $\left(\right.$ at $\left.0{ }^{\circ} \mathrm{C}\right)$ & $\mu_{\mathrm{P}_{\mathrm{O}} 0}$ & 0.014 & $\mathrm{~d}^{-1}$ \\
Diazotrophs' growth rate handicap & $c_{\text {Diaz }}$ & 0.13 & $\mathrm{~d}^{-1}$ \\
Diazotroph specific mortality rate & $\nu_{\mathrm{P}_{\text {Diaz }}}$ & 0.025 & $\mathrm{~d}^{-1}$ \\
Diazotroph fast-recycling rate $\left(\right.$ at $\left.0{ }^{\circ} \mathrm{C}\right)$ & $\mu_{\mathrm{P}_{\text {Diaz }} 0}$ & 0.0016 & $\mathrm{~d}^{-1}$ \\
\hline
\end{tabular}

\begin{tabular}{|c|c|c|c|}
\hline \multicolumn{4}{|c|}{ Zooplankton (Z) coefficients } \\
\hline Assimilation efficiency & $\gamma$ & 0.925 & \\
\hline Maximum grazing rate & $g$ & 1.575 & $d^{-1}$ \\
\hline Phytoplankton prey-capture rate & $\omega_{\mathrm{P}_{\mathrm{O}}}$ & 5.0 & $\left(\mathrm{mmol} \mathrm{m}{ }^{-3}\right)^{-2} \mathrm{~d}^{-1}$ \\
\hline Diazotroph prey-capture rate & $\omega_{P_{\text {Diaz }}}$ & 0.125 & $\left(\mathrm{mmol} \mathrm{m}{ }^{-3}\right)^{-2} \mathrm{~d}^{-1}$ \\
\hline Mortality & $v_{Z}$ & 0.34 & $\left(\mathrm{mmol} \mathrm{m} \mathrm{m}^{-3}\right)^{-2} \mathrm{~d}^{-1}$ \\
\hline Excretion $\left(\right.$ at $\left.0{ }^{\circ} \mathrm{C}\right)$ & $\mu_{\mathrm{Z} 0}$ & 0.015 & $d^{-1}$ \\
\hline \multicolumn{4}{|c|}{ Detritus (D) coefficients } \\
\hline Remineralization rate $\left(\right.$ at $0^{\circ} \mathrm{C}$ ) & $\mu_{\mathrm{D} 0}$ & 0.065 & $d^{-1}$ \\
\hline Sinking speed at surface & $w_{\mathrm{D} 0}$ & 13 & $\mathrm{md}^{-1}$ \\
\hline Increase of sinking speed with depth & $m_{w}$ & 0.06 & $\mathrm{~d}^{-1}$ \\
\hline E-folding temperature of biological rates & $T_{\mathrm{b}}$ & 15.65 & ${ }^{\circ} \mathrm{C}$ \\
\hline
\end{tabular}

\begin{tabular}{lcr}
\hline & Elemental ratios & \\
Molar oxygen : nitrogen & $R_{\mathrm{O}: \mathrm{N}}$ & 10.6 \\
Molar carbon : nitrogen & $R_{\mathrm{C}: \mathrm{N}}$ & 6.625 \\
Phytoplankton nitrogen : phosphorus & $\mathrm{N}: \mathrm{P}_{\mathrm{P}_{\mathrm{O}}}$ & 16 \\
Diazotroph nitrogen : phosphorus & $\mathrm{N}: \mathrm{P}_{\mathrm{P}_{\text {Diaz }}}$ & 40 \\
Zooplankton nitrogen : phosphorus & $\mathrm{N}: \mathrm{P}_{Z}$ & 16 \\
\hline
\end{tabular}

* Ecosystem-biogeochemistry parameter list for experiment \#3 (limWCD $\left.=32, \varepsilon_{\mathrm{BD}}=0\right)$. See Table 1 for changes to parameters for other experiments.

where $\beta=\alpha \cdot R_{\text {sub }}=R_{\text {sub }}(1-\varepsilon / 1000)$, consistent with Eq. (A4). Solving for benthic to WCD ratio yields

$\frac{\mathrm{BD}}{\mathrm{WCD}}=\frac{\left(\frac{\beta}{1+\beta}\right)_{\mathrm{NFix}}-\left(\frac{\beta}{1+\beta}\right)_{\mathrm{WCD}}}{\left(\frac{\beta}{1+\beta}\right)_{\mathrm{BD}}-\left(\frac{\beta}{1+\beta}\right)_{\mathrm{NFix}}}$

These results are displayed in Table 4 and Fig. 6.

\section{Appendix B}

\section{Marine ecosystem-biogeochemistry model description}

This appendix provides a description of the parameters used in the full set of time-dependent equations in the marine ecosystem model. It suffices to note that the equations for to- tal nitrogen $\left({ }^{14} \mathrm{~N}+{ }^{15} \mathrm{~N}\right)$ ecosystem variables are identical to the ones of ${ }^{15} \mathrm{~N}$ if $R_{X}=\beta_{X} /\left(1+\beta_{X}\right)=1$, which are located in Appendix A.

The function $J_{\mathrm{O}}^{*}$ provides the growth rate of nondiazotrophic "ordinary" phytoplankton, determined from irradiance $(I), \mathrm{NO}_{3}^{-}$and $\mathrm{PO}_{4}^{3-}$.

$J_{\mathrm{O}}^{*}\left(I, \mathrm{NO}_{3}^{-}, \mathrm{PO}_{4}^{3-}\right)=\min \left(J_{\mathrm{OI}}^{*}, J_{\mathrm{O} \max }^{*} u_{\mathrm{N}}, J_{\mathrm{O} \max }^{*} u_{\mathrm{P}}\right)$

The maximum growth rate is dependent only on temperature $(T)$,

$J_{\text {Omax }}^{*}=a_{0} \cdot \exp \left(T / T_{\mathrm{b}}\right)$,

such that growth rates increase by a factor of ten over the temperature range of -2 to $34^{\circ} \mathrm{C}$. Note that all terms with temperature dependency are denoted with the star symbol 


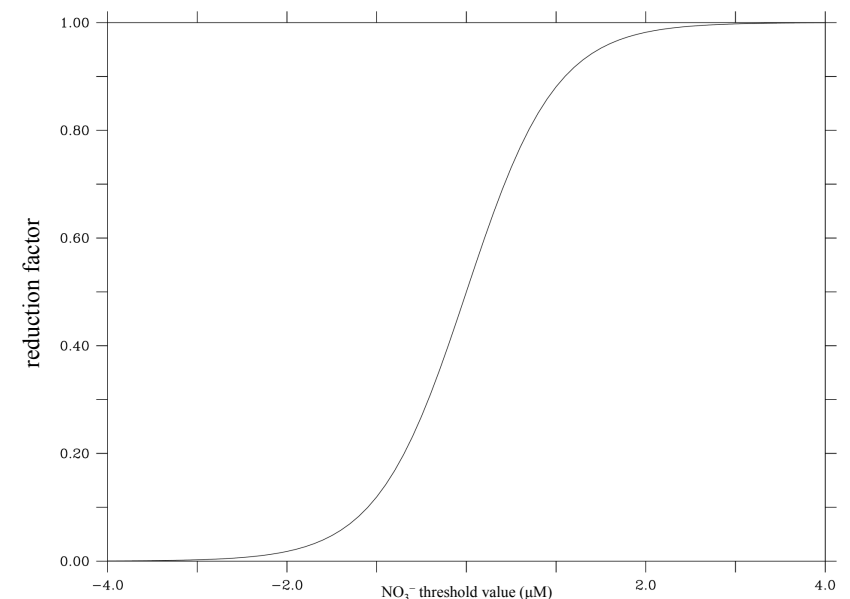

Fig. B1. Reduction factor applied to water column denitrification for given $\mathrm{NO}_{3}^{-}$concentration $(\mu \mathrm{M})$ thresholds.

$\left.{ }^{*}\right)$. We use $a_{0}=0.35 \mathrm{~d}^{-1}$ for the maximum growth rate at $0{ }^{\circ} \mathrm{C}$ which was determined to optimize surface nutrient concentrations. Under nutrient-replete conditions, the lightlimited growth rate $J_{\mathrm{OI}}$ is calculated according to

$J_{\mathrm{OI}}^{*}=\frac{J_{\mathrm{Omax}}^{*} \alpha I}{\left[J_{\mathrm{Omax}}^{* 2}+(\alpha I)^{2}\right]^{1 / 2}}$,

where $\alpha$ is the initial slope of the photosynthesis vs. irradiance (P-I) curve. The calculation of the photosynthetically active shortwave radiation $I$ and the method of averaging Eq. (B3) over one day is outlined in Schmittner et al. (2005). This version also includes the correction for the error in the calculation of light limitation in previous versions (Schmittner et al., 2008). Nutrient limitation is represented by the product of $J_{\mathrm{Omax}}^{*}$ and the nutrient uptake rates, $u_{\mathrm{N}}=\mathrm{NO}_{3}^{-} /\left(k_{\mathrm{N}}+\mathrm{NO}_{3}^{-}\right)$and $u_{\mathrm{P}}=\mathrm{PO}_{4}^{3-} /\left(k_{\mathrm{P}}+\mathrm{PO}_{4}^{3-}\right)$, with $k_{\mathrm{P}}=k_{\mathrm{N}} r_{\mathrm{P}: \mathrm{N}}$ providing the respective nutrient uptake rates.

Diazotrophs grow according to the same principles as the ordinary phytoplankton class, but are disadvantaged in nitrate-bearing waters by a lower maximum growth rate, $J_{\text {Diazmax }}^{*}$ :

$J_{\text {Diazmax }}^{*}=c_{\text {Diaz }} \cdot \operatorname{FeLim} \cdot a_{0} \cdot \exp \left(T / T_{\mathrm{b}}\right)$.

The coefficient $c_{\text {Diaz }}$ handicaps diazotrophs by dampening the increase of their maximal growth rate versus that of the general phytoplankton class with rising temperature. We use $c_{\text {Diaz }}=0.13$, such that the growth rate of diazotrophs is $13 \%$ that of ordinary phytoplankton. This handicap is further decreased by the Fe limitation parameter, which is scaled between 0 and 1 by multiplying a monthly climatology of aeolian dust deposition (Mahowald et al., 2005b, 2006, 2009) by a constant factor and setting the maximum value to 1 (Somes et al., 2010a). However, diazotrophs have an advantage in that their growth rate is not limited by $\mathrm{NO}_{3}^{-}$concentrations,

$J_{\text {Diaz }}^{*}\left(I, \mathrm{PO}_{4}\right)=\min \left(J_{\text {DiazI }}^{*}, J_{\text {Diazmax }}^{*} u_{\mathrm{P}}\right)$, although they do take up $\mathrm{NO}_{3}^{-}$if it is available (see term 1 on the right hand side of Eq. A7). The $\mathrm{N}: \mathrm{P}$ of model diazotrophs is set to $40: 1$.

The first-order mortality rates of phytoplankton and diazotrophs are linearly dependent on their biomass concentrations, $\mathrm{P}_{\mathrm{O}}$ and $\mathrm{P}_{\mathrm{Diaz}}$. Dissolved organic matter and the microbial loop are folded into a single fast-remineralization process, which is the product of their biomass and the temperature dependent term.

$\mu * \mathrm{P}_{\mathrm{O}}=\mu_{\mathrm{P}_{\mathrm{O}} 0} \exp \left(T / T_{\mathrm{b}}\right)$

Diazotrophs also die at a linear rate, which is included in this fast-remineralization process.

$\mu_{\mathrm{P}_{\text {Diaz }}}^{*}=\mu_{\mathrm{P}_{\mathrm{Diaz}} 0} \exp \left(T / T_{\mathrm{b}}\right)$

The grazing of ordinary phytoplankton by zooplankton remains unchanged from Schmittner et al. (2005) as follows:

$G\left(\mathrm{P}_{\mathrm{O}}\right)=\frac{g \omega_{\mathrm{P}_{\mathrm{O}}} \mathrm{P}_{\mathrm{O}}^{2}}{g+\omega_{\mathrm{P}_{\mathrm{O}}} \mathrm{P}_{\mathrm{O}}^{2}}$,

where $g$ is grazing rate, $\omega$ is prey-capture rate, and $\mathrm{P}$ is phytoplankton concentration (Table B1). Note prey-capture rate is reduced for diazotrophs relative to ordinary phytoplankton in these experiments (Table 1).

Since diazotrophs have a higher $\mathrm{N}: \mathrm{P}$ ratio $\left(\mathrm{N}: \mathrm{P}_{\text {Diaz }}=40\right)$ compared to zooplankton $\left(\mathrm{N}: \mathrm{P}_{\mathrm{Z}}=16\right)$, this excess $\mathrm{N}$ is instantaneously excreted to nitrate. The grazing formulation for diazotrophs becomes

$G\left(\mathrm{P}_{\text {Diaz }}\right)=\frac{g \omega_{\text {Diaz }} \mathrm{P}_{\text {Diaz }}^{2}}{g+\omega_{\text {Diaz }} \mathrm{P}_{\text {Diaz }}^{2}}\left(\frac{\mathrm{N}: \mathrm{P}_{\text {Zoop }}}{\mathrm{N}: \mathrm{P}_{\mathrm{P}_{\text {Diaz }}}}\right)$,

with the instantaneous grazing excretion (GE) term,

$\mathrm{GE}\left(\mathrm{P}_{\text {Diaz }}\right)=\frac{g \omega_{\text {Diaz }} \mathrm{P}_{\text {Diaz }}^{2}}{g+\omega_{\text {Diaz }} \mathrm{P}_{\text {Diaz }}^{2}}\left(1-\frac{\mathrm{N}: \mathrm{P}_{\text {Zoop }}}{\mathrm{N}: \mathrm{P}_{\mathrm{P}_{\text {Diaz }}}}\right)$,

routed directly to nitrate.

Detritus is generated from sloppy zooplankton feeding and mortality among the three classes of plankton, and is the only component of the ecosystem model to sink. It does so at a speed of

$w_{\mathrm{D}}=\left\{\begin{array}{c}w_{\mathrm{D} 0}+m_{w} z, z \leq 1000 \mathrm{~m} \\ w_{\mathrm{D} 0}+m_{w} 1000 \mathrm{~m}, z>1000 \mathrm{~m}\end{array}\right\}$,

increasing linearly with depth $z$ from $w_{\mathrm{D} 0}=7 \mathrm{~m} \mathrm{~d}^{-1}$ at the surface to $40 \mathrm{~m} \mathrm{~d}^{-1}$ at $1 \mathrm{~km}$ depth and constant below that, consistent with observations (Berelson, 2001). The remineralization rate of detritus is temperature dependent and decreases by a factor of 2 in suboxic waters, as $\mathrm{O}_{2}$ decreases from $10 \mu \mathrm{M}$ to $0 \mu \mathrm{M}$ :

$\mu_{\mathrm{D}}^{*}=\mu_{\mathrm{D} 0} \exp \left(T / T_{\mathrm{b}}\right)\left[0.75+0.25 \tanh \left(\mathrm{O}_{2}-6\right)\right]$. 

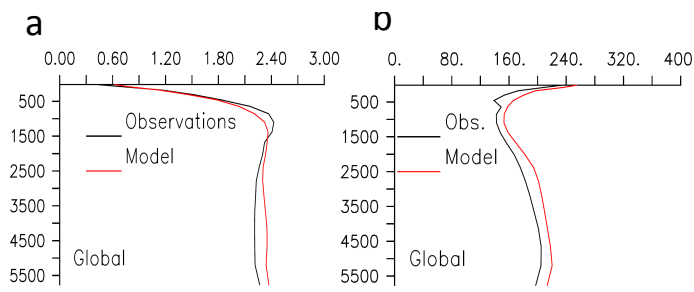

C
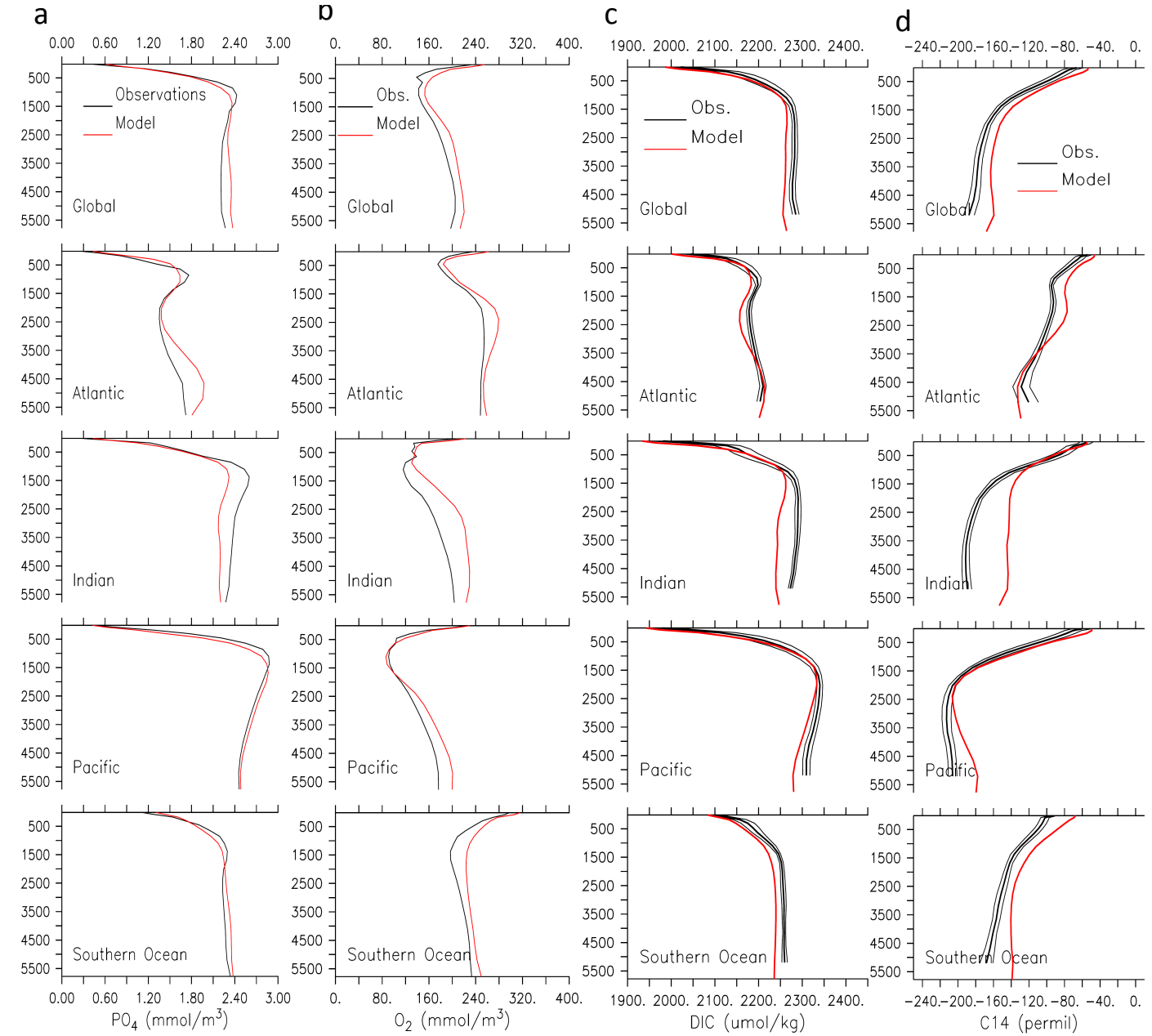

Fig. B2. Basin-scale model-data comparison of (a) $\mathrm{PO}_{4}^{-}$, (b) $\mathrm{O}_{2}$, (c) apparent oxygen utilization $(\mathrm{AOU})$, and $(\mathbf{d}) \Delta^{14} \mathrm{C}$ with limWCD $=32$, $\varepsilon_{\mathrm{BD}}=2$, model experiment $\# 5$.

Remineralization transforms the $\mathrm{N}$ and $\mathrm{P}$ content of detritus to $\mathrm{NO}_{3}^{-}$and $\mathrm{PO}_{4}^{3-}$. Photosynthesis produces oxygen, while respiration consumes oxygen, at rates equal to the consumption and remineralization rates of $\mathrm{PO}_{4}$, respectively, multiplied by the constant ratio $R_{\mathrm{O}} \mathrm{P}$. Dissolved oxygen exchanges with the atmosphere in the surface layer $\left(F_{\text {sfc }}\right)$ according to the Ocean Carbon-Cycle Model Intercomparison Project protocol (Orr, 1999).

Oxygen consumption in suboxic waters $\left(\mathrm{O}_{2}<\sim 5 \mu \mathrm{M}\right)$ is inhibited, according to

$r_{\mathrm{sox}}^{\mathrm{O}_{2}}=0.5\left[\tanh \left(\mathrm{O}_{2}-5\right)+1\right]$,

but is replaced by the oxygen-equivalent oxidation of nitrate,

$r_{\mathrm{sox}}^{\mathrm{NO}_{3}}=0.5\left[1-\tanh \left(\mathrm{O}_{2}-5\right)\right]$.

Denitrification consumes nitrate at a rate of $80 \%$ of the oxygen equivalent rate, as $\mathrm{NO}_{3}^{-}$is a more efficient oxidant on a mol per mol basis (i.e., one mol of $\mathrm{NO}_{3}^{-}$can accept $5 e^{-}$ while $1 \mathrm{~mol}$ of $\mathrm{O}_{2}$ can accept only $4 e^{-}$).

We include the scheme of Bohlen et al. (2012), which parameterizes $\mathrm{BD}$ based on the rain rate of $\mathrm{POC}\left(\mathrm{RR}_{\mathrm{POC}}\right)$ into the seafloor and bottom water oxygen and nitrate:

$$
\begin{aligned}
\mathrm{BD}= & \alpha_{\mathrm{BD}}\left(0.09782+0.22944 \times 0.9811^{\mathrm{bwO}_{2}-\mathrm{NO}_{3}^{-}}\right) \\
& \times \mathrm{RR}_{\mathrm{POC}} .
\end{aligned}
$$

$\mathrm{BD}$ is the rate at which nitrate is removed from the bottom water. We assume that the rain rate of carbon into the sediments occurs at a ratio of $R_{\mathrm{C}: \mathrm{N}}=6.625$ of the nitrogen in the sinking organic detritus.

Since the continental shelves and other small-scale bathymetric features are not well resolved in the model, we use a subgrid-scale parameterization. The portion of each bottom ocean grid box that is deeper than the real sea floor is calculated at each location from high-resolution $\left(1 / 5^{\circ}\right)$ bathymetry. The rain rate of carbon that is included in the $\mathrm{BD}$ function in this shelf parameterization is the amount of 
particulate organic carbon that sinks into the portion of the grid box covered by a shallower continental shelf. In the model, $\sim 30 \%$ of BD occurs within this shelf parameterization. The remaining particulate organic matter continues to sink to greater depths. The coarse-resolution physical circulation model's inability to fully resolve coastal systems generally underestimates primary production and sinking carbon fluxes on these continental shelves, which likely results in too-low $\mathrm{BD}$ rates there. To account for this deficiency, we multiply the BD transfer function by an arbitrary coefficient $\left(\alpha_{\mathrm{BD}}\right)$. This parameter is tuned to set the global deep ocean $\delta^{15} \mathrm{NO}_{3}^{-}$in the model to $\sim 5 \%$ o for each experiment. Figure 2 shows the spatial distribution of BD.

Acknowledgements. We thank the NICOPP working group for providing the seafloor $\delta^{15} \mathrm{~N}$ data and two anonymous reviewers for their helpful comments. C. J. Somes and A. Oschlies were supported by the Deutsche Forschungsgemeinschaft via the Sonderforschungsbereich 754 "Climate-Biogeochemistry Interactions in the Tropical Ocean". A. Schmittner was supported by grant OCE1131834 from the Marine Geology and Geophysics Program of the National Science Foundation.

The service charges for this open access publication

have been covered by a Research Centre of the

Helmholtz Association.

Edited by: K. Fennel

\section{References}

Alkhatib, M., Lehmann, M. F., and del Giorgio, P. A.: The nitrogen isotope effect of benthic remineralization-nitrificationdenitrification coupling in an estuarine environment, Biogeosciences, 9, 1633-1646, doi:10.5194/bg-9-1633-2012, 2012.

Altabet, M. A.: Constraints on oceanic $\mathrm{N}$ balance/imbalance from sedimentary ${ }^{15} \mathrm{~N}$ records, Biogeosciences, 4, 75-86, doi:10.5194/bg-4-75-2007, 2007.

Altabet, M. A., Francois, R., Murray, D. W., and Prell, W. L.: Climate-related variations in denitrification in the arabian sea from sediment ${ }^{15} \mathrm{~N} /{ }^{14} \mathrm{~N}$ ratios, Nature, 373, 506-509, 1995.

Altabet, M. A., Ryabenko, E., Stramma, L., Wallace, D. W. R., Frank, M., Grasse, P., and Lavik, G.: An eddy-stimulated hotspot for fixed nitrogen-loss from the Peru oxygen minimum zone, Biogeosciences, 9, 4897-4908, doi:10.5194/bg-9-48972012, 2012.

Antonov, J. I., Seidov, D., Boyer, T. P., Locarnini, R. A., Mishonov, A. V., Garcia, H. E., Baranova, O. K., Zweng, M. M., and Johnson, D. R.: World ocean atlas 2009, volume 2: Salinity, in: Noaa atlas nesdis 69, edited by: Levitus, S., US Government Printing Office, Washington, DC, 184, 2010.

Aumont, O., Maier-Reimer, E., Blain, S., and Monfray, P.: An ecosystem model of the global ocean including fe, si, p colimitations, Global Biogeochem. Cy., 17, 1060, doi:10.1029/2001gb001745, 2003.
Berelson, W. M.: Particle settling rates increase wth depth in the ocean, Deep-SeaRes. Pt. II, 49, 237-251, doi:10.1016/S09670645(01)00102-3, 2001.

Bianchi, D., Dunne, J. P., Sarmiento, J. L., and Galbraith, E. D.: Data-based estimates of suboxia, denitrification, and n2o production in the ocean and their sensitivities to dissolved $\mathrm{O}_{2}$, Global Biogeochem. Cy., 26, GB2009, doi:10.1029/2011gb004209, 2012.

Bohlen, L., Dale, A. W., and Wallmann, K.: Simple transfer functions for calculating benthic fixed nitrogen losses and $\mathrm{C}: \mathrm{N}: \mathrm{P}$ regeneration ratios in global biogeochemical models, Global Biogeochem. Cy., 26, GB3029, doi:10.1029/2011gb004198, 2012.

Brandes, J. A., Devol, A. H., Yoshinari, T., Jayakumar, D. A., and Naqvi, S. W. A.: Isotopic composition of nitrate in the central arabian sea and eastern tropical north pacific: A tracer for mixing and nitrogen cycles, Limnnol. Oceanogr., 43, 1680-1689, 1998.

Brandes, J. A. and Devol, A. H.: A global marine-fixed nitrogen isotopic budget: Implications for holocene nitrogen cycling, Global Biogeochem. Cy., 16, 1120, doi:10.1029/2001GB001856, 2002.

Bulow, S. E., Rich, J. J., Naik, H. S., Pratihary, A. K., and Ward, B. B.: Denitrification exceeds anammox as a nitrogen loss pathway in the arabian sea oxygen minimum zone, Deep-SeaRes. Pt. I, 57, 384-393, 2010.

Cline, J. D. and Kaplan, I. R.: Isotopic fractionation of dissolved nitrate during denitrification in the eastern tropical north pacific ocean, Mar. Chem., 3, 271-299, 1975.

Codispoti, L. A.: An oceanic fixed nitrogen sink exceeding $400 \mathrm{Tg} \mathrm{N} \mathrm{a}^{-1}$ vs the concept of homeostasis in the fixed-nitrogen inventory, Biogeosciences, 4, 233-253, doi:10.5194/bg-4-2332007, 2007.

Codispoti, L. A., Brandes, J. A., Christensen, J. P., Devol, A. H., Naqvi, S. W. A., Paerl, H. W., and Yoshinari, T.: The oceanic fixed nitrogen and nitrous oxide budgets: Moving targets as we enter the anthropocene?, Sci. Mar., 65, 85-105, doi:10.3989/scimar.2001.65s 285, 2001.

Deutsch, C., Sigman, D. M., Thunell, R. C., Meckler, A. N., and Haug, G. H.: Isotopic constraints on glacial/interglacial changes in the oceanic nitrogen budget, Global Biogeochem. Cy., 18, GB4012, doi:10.1029/2003gb002189, 2004.

Deutsch, C., Sarmiento, J. L., Sigman, D. M., Gruber, N., and Dunne, J. P.: Spatial coupling of nitrogen inputs and losses in the ocean, Nature, 11, 163-167, 2007.

DeVries, T., Deutsch, C., Rafter, P. A., and Primeau, F.: Marine denitrification rates determined from a global 3-D inverse model, Biogeosciences, 10, 2481-2496, doi:10.5194/bg-10-2481-2013, 2013.

Duce, R. A., LaRoche, J., Altieri, K., Arrigo, K. R., Baker, A. R., Capone, D. G., Cornell, S., Dentener, F., Galloway, J., Ganeshram, R. S., Geider, R. J., Jickells, T., Kuypers, M. M., Langlois, R., Liss, P. S., Liu, S. M., Middelburg, J. J., Moore, C. M., Nickovic, S., Oschlies, A., Pedersen, T., Prospero, J., Schlitzer, R., Seitzinger, S., Sorensen, L. L., Uematsu, M., U1loa, O., Voss, M., Ward, B., and Zamora, L.: Impacts of atmospheric anthropogenic nitrogen on the open ocean, Science, 320, 893-897, doi:10.1126/science.1150369, 2008.

Eby, M., Zickfeld, K., Montenegro, A., Archer, D., Meissner, K. J., and Weaver, A. J.: Lifetime of anthropogenic climate change: Millennial time scales of potential $\mathrm{CO}_{2}$ and surface temperature perturbations, J. Climate, 22, 2501-2511, 
doi:10.1175/2008jcli2554.1, 2009.

Eugster, O. and Gruber, N.: A probabilistic estimate of global marine n-fixation and denitrification, Global Biogeochem. Cy., 26, GB4013, doi:10.1029/2012gb004300, 2012.

Falkowski, P. G.: Evolution of the nitrogen cycle and its influence on the biological sequestration of co2 in the ocean, Nature, 387, 272-275, 1997.

Fennel, K., Wilkin, J., Levin, J., Moisan, J., O’Reilly, J., and Haidvogel, D.: Nitrogen cycling in the middle atlantic bight: Results from a three-dimensional model and implications for the north atlantic nitrogen budget, Global Biogeochem. Cy., 20, GB3007, doi:10.1029/2005GB002456, 2006.

Fennel, K., Brady, D., DiToro, D., Fulweiler, R., Gardner, W., Giblin, A., McCarthy, M., Rao, A., Seitzinger, S., ThouvenotKorppoo, M., and Tobias, C.: Modeling denitrification in aquatic sediments, Biogeochemistry, 93, 159-178, doi:10.1007/s10533008-9270-z, 2009.

Foster, R. A., Kuypers, M. M. M., Vagner, T., Paerl, R. W., Musat, N., and Zehr, J. P.: Nitrogen fixation and transfer in open ocean diatom-cyanobacterial symbioses, ISME J., 5, 1484-1493, 2011.

Galbraith, E. D. and Kienast, M.: The acceleration of oceanic denitrification during deglacial warming, Nat. Geosci., 6, 579-584, doi:10.1038/ngeo1832, 2013.

Galbraith, E. D., Gnanadesikan, A., Dunne, J. P., and Hiscock, M. R.: Regional impacts of iron-light colimitation in a global biogeochemical model, Biogeosciences, 7, 1043-1064, doi:10.5194/bg-7-1043-2010, 2010.

Galloway, J. N., Dentener, F. J., Capone, D. G., Boyer, E. W., Howarth, R. W., Seitzinger, S. P., Asner, G. P., Cleveland, C. C., Green, P. A., Holland, E. A., Karl, D. M., Michaels, A. F., Porter, J. H., Townsend, A. R., and Vöosmarty, C. J.: Nitrogen cycles: Past, present, and future, Biogeochemistry, 70, 153-226, doi:10.1007/s10533-004-0370-0, 2004.

Garcia, H. E., Locarnini, R. A., Boyer, T. P., Antonov, J. I., Baranov, O. K., Zweng, M. M., and Johnson, D. R.: World ocean atlas 2009, volume 3: Dissolved oxygen, apparent oxygen utilization, and oxygen saturation, in: Noaa atlas nesdis 70, edited by: Levitus, S., US Government Printing Office, Washington, DC, 344, 2010a.

Garcia, H. E., Locarnini, R. A., Boyer, T. P., Antonov, J. I., Zweng, M. M., Baranov, O. K., and Johnson, D. R.: World ocean atlas 2009, volume 4: Nutrients (phosphate, nitrate, silicate), in: Noaa atlas nesdis 71, edited by: Levitus, S., US Government Printing Office, Washington, DC, 398, 2010b.

Gent, P. R. and McWilliams, J. C.: Isopycnal mixing in ocean circulation models, Journal of Physical Oceanography, 20, 150-155, doi:10.1175/1520-0485(1990)020<0150:IMIOCM > 2.0.CO;2, 1990.

Giraud, X., Bertrand, P., Garc, on, V., and Dadou, I.: Modeling delta15n evolution: First palaeoceanographic applications in a coastal upwelling system, J. Mar. Res., 58, 609-630, 2000.

Gnanadesikan, A., Dunne, J. P., and John, J.: Understanding why the volume of suboxic waters does not increase over centuries of global warming in an Earth System Model, Biogeosciences, 9, 1159-1172, doi:10.5194/bg-9-1159-2012, 2012.

Granger, J., Prokopenko, M. G., Sigman, D. M., Mordy, C. W., Morse, Z. M., Morales, L. V., Sambrotto, R. N., and Plessen, B.: Coupled nitrification-denitrification in sediment of the eastern bering sea shelf leads to ${ }^{15} \mathrm{~N}$ enrichment of fixed $\mathrm{n}$ in shelf wa- ters, J. Geophys. Res., 116, C11006, doi:10.1029/2010jc006751, 2011.

Großkopf, T., Mohr, W., Baustian, T., Schunck, H., Gill, D., Kuypers, M. M. M., Lavik, G., Schmitz, R. A., Wallace, D. W. R., and LaRoche, J.: Doubling of marine dinitrogen-fixation rates based on direct measurements, Nature, 488, 361-364, http://www.nature.com/nature/journal/v488/ n7411/abs/nature11338.html-supplementary-information, 2012.

Gruber, N.: The dynamics of the marine nitrogen cycle and its influence on atmospheric $\mathrm{CO}_{2}$ variations, in: The ocean carbon cycle and climate, IV Edn., edited by: Follows, M. and Oguz, T., Nato science series, Kluwer Academics, Dordrecht, 97-148, 2004.

Gruber, N.: Chapter 1 - the marine nitrogen cycle: Overview and challenges, in: Nitrogen in the marine environment, 2nd Edn., Academic Press, San Diego, 1-50, 2008.

Gruber, N. and Sarmiento, J. L.: Global patterns of marine nitrogen fixation and denitrification, Global Biogeochem. Cy., 11, 235266, 1997.

Holl, C. M., and Montoya, J. P.: Interactions between nitrate uptake and nitrogen fixation in continuous cultures of the marine diazotroph trichodesmium (cyanobacteria), J. Phycol., 41, 11781183, doi:10.1111/j.1529-8817.2005.00146.x, 2005.

Kalnay, E., Kanamitsu, M., Kistler, R., Collins, W., Deaven, D., Gandin, L., Iredell, M., Saha, S., White, G., Woollen, J., Zhu, Y., Leetmaa, A., Reynolds, R., Chelliah, M., Ebisuzaki, W., Higgins, W., Janowiak, J., Mo, K. C., Ropelewski, C., Wang, J., Jenne, R., and Joseph, D.: The ncep/ncar 40-year reanalysis project, B. Am. Meteorol. Soc., 77, 437-471, doi:10.1175/15200477(1996)077<0437:tnyrp>2.0.co;2, 1996.

Karl, D., Michaels, A., Bergman, B., Capone, D., Carpenter, E., Letelier, R., Lipschultz, F., Paerl, H., Sigman, D., and Stal, L.: Dinitrogen fixation in the world's oceans, Biogeochemistry, 5758, 47-98, doi:10.1023/a:1015798105851, 2002a.

Karl, D., Michaels, A., Bergman, B., Capone, D., Carpenter, E., Letelier, R., Lipshultz, F., Paerl, H., Sigman, D., and Stal, L.: Dinitrogen fixation in the world's oceans, Biogeochemistry, 57/58, 47-98, 2002b.

Klausmeier, C. A., Litchman, E., Daufresne, T., and Levin, S. A.: Optimal nitrogen-to-phosphorus stoichiometry of phytoplankton, Nature, 429, 171-174, http://www.nature.com/nature/ journal/v429/n6988/suppinfo/nature02454_S1.html, 2004.

Kuypers, M. M. M., Sliekers, A. O., Lavik, G., Schmid, M., Jorgensen, B. B., Kuenen, J. G., Sinninghe Damste, J. S., Strous, M., and Jetten, M. S. M.: Anaerobic ammonium oxidation by anammox bacteria in the black sea, Nature, 422, 608-611, 2003.

Kuypers, M. M. M., Lavik, G., Woebken, D., Schmid, M., Fuchs, B. M., Amann, R., Jørgensen, B. B., and Jetten, M. S. M.: Massive nitrogen loss from the benguela upwelling system through anaerobic ammonium oxidation, P. Natl. Acad. Sci. USA, 102, 6478-6483, doi:10.1073/pnas.0502088102, 2005.

Lam, P., Lavik, G., Jensen, M. M., van de Vossenberg, J., Schmid, M., Woebken, D., Gutiérrez, D., Amann, R., Jetten, M. S. M., and Kuypers, M. M. M.: Revising the nitrogen cycle in the peruvian oxygen minimum zone, P. Natl. Acad. Sci. USA, 106, 47524757, doi:10.1073/pnas.0812444106, 2009.

Large, W. G., Danabasoglu, G., McWilliams, J. C., Gent, P. R., and Bryan, F. O.: Equatorial circulation of a global ocean climate model with anisotropic horizontal viscosity, J. Phys. Oceanogr., 31, 518-536, doi:10.1175/1520- 
0485(2001)031<0518:ECOAGO > 2.0.CO;2, 2001.

Lehmann, M. F., Sigman, D. M., and Berelson, W. M.: Coupling the ${ }^{15} \mathrm{~N} /{ }^{14} \mathrm{~N}$ and ${ }^{18} \mathrm{O} /{ }^{16} \mathrm{O}$ of nitrate as a constraint on benthic nitrogen cycling, Mar. Chem., 88, 1-20, 2004.

Lehmann, M. F., Sigman, D. M., McCorkle, D. C., Granger, J., Hoffmann, S., Cane, G., and Brunelle, B. G.: The distribution of nitrate ${ }^{15} \mathrm{~N} /{ }^{14} \mathrm{~N}$ in marine sediments and the impact of benthic nitrogen loss on the isotopic composition of oceanic nitrate, Geochim. Cosmochim. Ac., 71, 5384-5404, 2007.

Le Quéré, C. L., Harrison, S. P., Colin Prentice, I., Buitenhuis, E. T., Aumont, O., Bopp, L., Claustre, H., Cotrim Da Cunha, L., Geider, R., Giraud, X., Klaas, C., Kohfeld, K. E., Legendre, L., Manizza, M., Platt, T., Rivkin, R. B., Sathyendranath, S., Uitz, J., Watson, A. J., and Wolf-Gladrow, D.: Ecosystem dynamics based on plankton functional types for global ocean biogeochemistry models, Glob. Change Biol., 11, 2016-2040, doi:10.1111/j.13652486.2005.1004.x, 2005.

Letelier, R. M. and Karl, D. M.: Trichodesmium spp. Physiology and nutrient fluxes in the north pacific subtropical gyre, Aquat. Microb. Ecol., 15, 265-276, doi:10.3354/ame015265, 1998.

Locarnini, R. A., Mishonov, A. V., Antonov, J. I., Boyer, T. P., Garcia, H. E., Baranova, O. K., Zweng, M. M., and Johnson, D. R.: World ocean atlas 2009, volume 1: Temperature, in: Noaa atlas nesdis 68, edited by: Levitus, S., US Government Printing Office, Washington, DC, 184, 2010.

Mahaffey, C., Michaels, A. F., and Capone, D. G.: The conundrum of marine n2 fixation, Am. J. Sci., 305, 546-595, doi:10.2475/ajs.305.6-8.546, 2005.

Mahowald, N. M., Baker, A. R., Bergametti, G., Brooks, N., Duce, R. A., Jickells, T. D., Kubilay, N., Prospero, J. M., and Tegen, I.: Atmospheric global dust cycle and iron inputs to the ocean, Global Biogeochem. Cy., 19, GB4025, doi:10.1029/2004gb002402, 2005a.

Mahowald, N. M., Baker, A. R., Bergametti, G., Brooks, N., Duce, R. A., Jickells, T. D., Kubilay, N., Prospero, J. M., and Tegen, I.: Atmospheric global dust cycle and iron inputs to the ocean, Global Biogeochem. Cy., 19, GB4025, doi:10.1029/2004GB002402, 2005b.

Mahowald, N. M., Muhs, D. R., Levis, S., Rasch, P. J., Yoshioka, M., Zender, C. S., and Luo, C.: Change in atmospheric mineral aerosols in response to climate: Last glacial period, preindustrial, modern, and doubled carbon dioxide climates, J. Geophys. Res., 111, D10202, doi:10.1029/2005jd006653, 2006.

Mahowald, N. M., Engelstaedter, S., Luo, C., Sealy, A., Artaxo, P., Benitez-Nelson, C., Bonnet, S., Chen, Y., Chuang, P. Y., Cohen, D. D., Dulac, F., Herut, B., Johansen, A. M., Kubilay, N., Losno, R., Maenhaut, W., Paytan, A., Prospero, J. A., Shank, L. M., and Siefert, R. L.: Atmospheric iron deposition: Global distribution, variability, and human perturbations, in: Annual review of marine science, Annual review of marine science, Annual Reviews, Palo Alto, 245-278, 2009.

Mariotti, A., Germon, J., Hubert, P., Kaiser, P., Letolle, R., Tardieux, A., and Tardieux, P.: Experimental determination of nitrogen kinetic isotope fractionation: Some principles; illustration for the denitrification and nitrification processes, Plant Soil, 62, 413430, doi:10.1007/bf02374138, 1981.

McElroy, M. B.: Marine biological controls on atmospheric co2 and climate, Nature, 302, 328-329, 1983.
Middelburg, J. J., Soetaert, K., Herman, P. M. J., and Heip, C. H. R.: Denitrification in marine sediments: A model study, Global Biogeochem. Cy., 10, 661-673, doi:10.1029/96gb02562, 1996.

Mohr, W., Großkopf, T., Wallace, D. W. R., and LaRoche, J.: Methodological underestimation of oceanic nitrogen fixation rates, PLoS ONE, 5, e12583, doi:10.1371/journal.pone.0012583, 2010.

Monteiro, F. M., Dutkiewicz, S., and Follows, M. J.: Biogeographical controls on the marine nitrogen fixers, Global Biogeochem. Cy., 25, GB2003, doi:10.1029/2010gb003902, 2011.

Montoya, J. P., Holl, C. M., Zehr, J. P., Hansen, A., Villareal, T. A., and Capone, D. G.: High rates of $\mathrm{n} 2$ fixation by unicellular diazotrophs in the oligotrophic pacific ocean, Nature, 430, 10271032, 2004.

Moore, J. K., Doney, S. C., and Lindsay, K.: Upper ocean ecosystem dynamics and iron cycling in a global threedimensional model, Global Biogeochem. Cy., 18, GB4028, doi:10.1029/2004gb002220, 2004.

Moore, J. K. and Doney, S. C.: Iron availability limits the ocean nitrogen inventory stabilizing feedbacks between marine denitrification and nitrogen fixation, Global Biogeochem. Cy., 21, GB2001, doi:10.1029/2006gb002762, 2007.

Mulholland, M. R.: The fate of nitrogen fixed by diazotrophs in the ocean, Biogeosciences, 4, 37-51, doi:10.5194/bg-4-37-2007, 2007.

Mulholland, M. R., Ohki, K., and Capone, D. G.: Nutrient controls on nitrogen uptake and metabolism by natural populations and cultures of trichodesmium (cyanobacteria), J. Phycol., 37, 10011009, 2001.

Orr, J. C.: Ocean carbon-cycle model intercomparison project (ocmip): Pase 1 (1995-1997), GAIM Report, 7, 1999.

Pandey, K. D., Shukla, S. P., Shukla, P. N., Giri, D. D., Singh, J. S., Singh, P., and Kashyap, A. K.: Cyanobacteria in antarctica: Ecology, physiology and cold adaptation, Cellular and molecular biology (Noisy-le-Grand, France), 50, 575-584, 2004.

Robinson, R. S., Kienast, M., Luiza Albuquerque, A., Altabet, M., Contreras, S., De Pol Holz, R., Dubois, N., Francois, R., Galbraith, E., Hsu, T.-C., Ivanochko, T., Jaccard, S., Kao, S.-J., Kiefer, T., Kienast, S., Lehmann, M., Martinez, P., McCarthy, M., Möbius, J., Pedersen, T., Quan, T. M., Ryabenko, E., Schmittner, A., Schneider, R., Schneider-Mor, A., Shigemitsu, M., Sinclair, D., Somes, C., Studer, A., Thunell, R., and Yang, J.-Y.: A review of nitrogen isotopic alteration in marine sediments, Paleoceanography, 27, PA4203, doi:10.1029/2012pa002321, 2012.

Ryabenko, E., Kock, A., Bange, H. W., Altabet, M. A., and Wallace, D. W. R.: Contrasting biogeochemistry of nitrogen in the Atlantic and Pacific Oxygen Minimum Zones, Biogeosciences, 9, 203215, doi:10.5194/bg-9-203-2012, 2012.

Sañudo-Wilhelmy, S. A., Tovar-Sanchez, A., Fu, F.-X., Capone, D. G., Carpenter, E. J., and Hutchins, D. A.: The impact of surfaceadsorbed phosphorus on phytoplankton redfield stoichiometry, Nature, 432, 897-901, http://www.nature.com/nature/journal/ v432/n7019/abs/nature03125.html-supplementary-information, 2004.

Schmittner, A., Oschlies, A., Giraud, X., Eby, M., and Simmons, H. L.: A global model of the marine ecosystem for long-term simulations: Sensitivity to ocean mixing buoyancy forcing, particle sinking, and dissolved organic matter cycling, Global Biogeochem. Cy., 19, GB3004, doi:10.1029/2004GB002283, 2005. 
Schmittner, A., Oschlies, A., Matthews, H. D., and Galbraith, E. G.: Future changes in climate, ocean circulation, ecosystems, and biogeochemical cycling simulated for a buisness-as-usual $\mathrm{CO}_{2}$ emission scenario until year 4000 ad, Global Biogeochem. Cy., 22, GB1013, doi:10.1029/2007GB002953, 2008.

Seitzinger, S., Harrison, J. A., Böhlke, J. K., Bouwman, A. F., Lowrance, R., Peterson, B., Tobias, C., and Drecht, G. V.: Denitrification across landscapes and waterscapes: A synthesis, Ecol. Appl., 16, 2064-2090, doi:10.1890/10510761(2006)016[2064:DALAWA]2.0.CO;2, 2006.

Sigman, D. M., Altabet, M. A., McCorkle, D. C., Francois, R., and Fischer, G.: The d15n of nitrate in the southern ocean: Nitrogen cycling and circulation in the ocean interior, J. Geophys. Res., 105, 19599-19614, doi:10.1029/2000jc000265, 2000.

Simmons, H. L., Jayne, S. R., Laurent, L. C. S., and Weaver, A. J.: Tidally driven mixing in a numerical model of the ocean general circulation, Ocean Model., 6, 245-263, doi:10.1016/S14635003(03)00011-8, 2004.

Somes, C. J., Schmittner, A., and Altabet, M. A.: Nitrogen isotope simulations show the importance of atmospheric iron deposition for nitrogen fixation across the pacific ocean, Geophys. Res. Lett., 37, L23605, doi:10.1029/2010g1044537, 2010a.

Somes, C. J., Schmittner, A., Galbraith, E. D., Lehmann, M. F., Altabet, M. A., Montoya, J. P., Letelier, R. M., Mix, A. C., Bourbonnais, A., and Eby, M.: Simulating the global distribution of nitrogen isotopes in the ocean, Global Biogeochem. Cy., 24, GB4019, doi:10.1029/2009gb003767, 2010b.

Sterner, R. W. and Elser, J. J.: Ecological stoichiometry: The biology of elements from molecules to the biosphere, Princeton University Press, 429 pp., 2002.
Subramaniam, A., Mahaffey, C., Johns, W., and Mahowald, N.: Equatorial upwelling enhances nitrogen fixation in the atlantic ocean, Geophys. Res. Lett., 40, 1766-1771, doi:10.1002/grl.50250, 2013.

Tesdal, J.-E., Galbraith, E. D., and Kienast, M.: Nitrogen isotopes in bulk marine sediment: linking seafloor observations with subseafloor records, Biogeosciences, 10, 101-118, doi:10.5194/bg10-101-2013, 2013.

Thamdrup, B. and Dalsgaard, T.: Production of n(2) through anaerobic ammonium oxidation coupled to nitrate reduction in marine sediments, Appl. Environ. Microb., 68, 1312-1318, 2002.

Voss, M., Dippner, J. W., and Montoya, J. P.: Nitrogen isotope patterns in the oxygen-deficient waters of the eastern tropical north pacific ocean, Deep-Sea Res. Pt. I, 48, 190-1921, 2001.

Ward, B. B., Devol, A. H., Rich, J. J., Chang, B. X., Bulow, S. E., Naik, H., Pratihary, A., and Jayakumar, A.: Denitrification as the dominant nitrogen loss process in the arabian sea, Nature, 461, 78-81, http://www.nature.com/nature/journal/v461/n7260/ suppinfo/nature08276_S1.html, 2009.

Weaver, A. J., Eby, M., Wiebe, E. C., Bitz, C. M., Duffy, P. B., Ewen, T. L., Fanning, A. F., Holland, M. M., MacFadyen, A., Matthews, H. D., Meissner, K. J., Saenko, O., Schmittner, A., Wang, H., and Yoshimori, M.: The uvic earth system climate model: Model description, climatology, and applications to past, present and future climates, Atmos. Ocean, 39, 361-428, 2001.

Zehr, J. P.: Nitrogen fixation by marine cyanobacteria, Trends Microbiol., 19, 162-173, 2011. 